Article

\title{
An Incentive-Based Solution of Sustainable Mobility for Economic Growth and $\mathrm{CO}_{2}$ Emissions Reduction
}

\author{
Manuel Herrador ${ }^{1, *}$, Alexandre Carvalho ${ }^{2}$ and Francisco R. Feito ${ }^{1}$ \\ 1 Department of Computer Science, University of Jaen, Paraje las Lagunillas, Jaen 23009, Spain; \\ E-Mail: ffeito@ujaen.es \\ 2 INESC Porto (USIC), INESC TEC_Campus da FEUP_Rua Dr. Roberto Frias, 4200-465 Porto, \\ Portugal; E-Mail: alexandre.carvalho@inescporto.pt \\ * Author to whom correspondence should be addressed; E-Mail: mherrador@ujaen.es; \\ Tel.: +34-600-812-007.
}

Academic Editor: Marc A. Rosen

Received: 11 February 2015 / Accepted: 6 May 2015 / Published: 19 May 2015

\begin{abstract}
Incentivized Sustainable Mobility" is a conceptual business model which involves four stakeholders: citizens, municipalities, commerce and mobility services. A platform named "ISUMO" (Incentivized Sustainable Mobility) provides technological support to this business model, integrating a set of metaservices that unifies the existing ICTs of transportation plus a unique patented QR-based (Quick Response) low-cost charging device for electric vehicles. Essentially, the system tracks and registers citizens' transportation activities (anonymously and voluntarily) and evaluates each through a scoring system while their ecological footprint is calculated. Afterwards, citizens are able to exchange their accumulated points for discount QR coupons, to be redeemed in the associated commerce in order to purchase their products or services. The breakthrough of this business model is that it enhances awareness of sustainable mobility practices, increasing their attractiveness as perceived by the stakeholders with diverse benefits; citizens (and indirectly, the municipalities) initiate a new consumption pattern of "coupons culture" linked to sustainable mobility, the urban economy is stimulated, and the use of mobility services grows, providing a new business opportunity regarding electric vehicles. It is expected that continuous exploration of the model and implementation will contribute to sustainable social and economic development aiming at $\mathrm{CO}_{2}$ emissions reduction, headline targets of the Europe 2020 strategy.
\end{abstract}


Keywords: sustainable mobility; incentivized sustainable mobility; transportation; Europe 2020; GIS; QR; environment

\section{Introduction}

In January 2015, over 2500 business policymakers, leaders and academics met at the World Economic Forum which took place in Davos (Switzerland) to discuss the need to look beyond current financial concerns and to focus on the effects of climate change [1]. In November 2014, the United Nations' Intergovernmental Panel on Climate Change (IPCC) released a new report wherein world emissions would have to fall by between $40 \%$ and $70 \%$ by 2050 from current levels and to "near zero or below in 2100" [2]. It is therefore important to tackle the current socio-economic and climate change challenges by putting more pressure on countries to transition to a low-carbon economy [3]. One of the areas which contributes with a large proportion of emissions while still undergoing rapid growth is transportation [4], which currently accounts for approximately $14 \%$ of overall global greenhouse gas emissions and $24 \%$ of the global $\mathrm{CO}_{2}$ emissions from fossil fuel combustion [5] (further discussion about such a widespread issue is not necessary). The authors feel that governments should therefore lead the way in promoting low carbon consumption activities, especially those related to public transportation [6].

The Horizon 2020 programme regarding transportation recently highlighted a great challenge related to multimodal integrated travel information, planning and ticketing services. The current fragmentation, dispersed knowledge and lack of cooperation between the stakeholders involved does not allow a user to easily organize a door-to-door pan-European intermodal trip while the emissions that will be caused by a specific travel choice are taken into account [7]. In response to this issue, the multimodal transportation approach is recognized as one of the best solutions to the spreading traffic congestion and need for sustainable mobility [8]. Meanwhile, it is also well accepted that information and information communication technology (ICT) will function as the nerve system of such multimodal transport solutions [9], making it possible to integrate carbon emission models in order to study the impact of transportation activities on the environment [3].

In sustainable mobility, electric vehicles significantly improve local air quality, hence they can be made nearly $\mathrm{CO}_{2}$-free, depending on the primary energy source used [10]. Electric mobility is confronted with several persisting barriers to market penetration, like the high purchase price, the limited range and the lack of charging infrastructure [11]. Despite these shortcomings, France, for instance, feels optimistic about electric vehicles, and the target there is to have 2 million by 2020 [12].

The idea is that a conceptual business model of sustainable mobility should require a broad set of environmental, economic and environmental indicators [13]. Therefore, the socio-economic effects of transportation should be considered seriously since they are highly critical to the quality of people's lives [14]. For instance, "Nuride" [15] is a US-based solution which rewards green trips (carpool, bike, walking, etc.) with discount coupons. However, there is no further technological validation, with the system depending entirely on the user's good faith and it being perfectly possible to cheat the system and obtain discounts from non-existing trips. 
This paper describes the conceptual business model as an approach to incentivizing sustainable mobility that intends to tackle some of the current issues mentioned above by encouraging the participation of the necessary stakeholders; citizens, municipalities, mobility solutions and commerce. ISUMO is the name given to the platform which supports the conceptual business model technologically, by implementing three modules and four sub-modules (see Table 1).

Table 1. Summary of the ISUMO platform's functionalities.

\begin{tabular}{ll}
\hline \multicolumn{1}{c}{ Module/Sub-Module } & \multicolumn{1}{c}{ Functionality } \\
\hline Mobility & Graphical interface with the community and mobility solutions. \\
- Metaservices & Geographic Information System (GIS) as a multimodal solution of transport. \\
- Electro mobility & A (patented) low-cost and QR-based charging device and its web solution. \\
\hline Business & Gives a score for using the previously mentioned mobility solutions. \\
- Tracker & Verifies whether the geo-tracked trips are realistic in order to grant a score. \\
- Sellers & Sellers create promotions and citizens exchange their scores for coupons. \\
\hline Environment & Calculates the carbon footprint of citizens' transportation activities. \\
\hline
\end{tabular}

This work presents an innovative sustainable business model linked to transportation and rewards, built on key literature and practice cases, including a partial implementation with the platform named "Recarga Jaen" [16]. One of the most important aims of this study is to be disseminated effectively in order to reach the greatest number of scholars, researchers and municipalities that could adopt or develop any of the ideas exposed here as a contribution to sustainable development linked to transportation.

The remainder of this document is organized as follows: Section 2 describes the incentivized sustainable mobility conceptual business model. Section 3 contains an overview of the proposed ISUMO's platform architecture that supports previous business models, including a real implementation of part of the platform, the Recarga Jaen project. Section 4 makes a comparison between two common scenarios of multimodal transportation and ISUMO, before the conclusions in Section 5.

\section{The Incentivized Sustainable Mobility Conceptual Business Model}

This section describes the methodology employed to build the Incentivized Sustainable Mobility Business Model. First, a revision of key literature is necessary where various authors have investigated business model innovation, sustainable business models for transportation and notable practice cases. Then, the Incentivized Sustainable Mobility Conceptual Business Model is built and described considering the previous key literature and notable practice cases.

\subsection{Introduction to Business Models}

Regarding business models, there are various classifications. A generic overview by Magretta [17] exposed that creating a business model is similar to writing a new story, where all new stories are really versions of old ones, and the model answers certain questions such as "Who is the customer?" or "How do we make money?". There is a more specific business model definition related to this paper's business model and introducing the concept of e-business by Amit and Zott [18], which highlighted the importance of adapting to a changing business scenario of virtual markets in order to open up new sources of innovation. Furthermore, Zott et al. [19] also carried out an extensive review of the literature on business 
models and contributed to this study in order to find one of the most accurate classifications that match with this work's ideas, proposed by Rappa [20], where the business model could be understood as a hybrid combining e-commerce and an Infomediary Model with Incentive Marketing. This is "a customer loyalty program that provides incentives to customers such as redeemable points or coupons for making purchases from associated retailers".

\section{How to describe a business model?}

Dobosson-Torbay et al. [21] describe a business model in the internet era (e-business), it includes four interconnected components: product innovation, customer relationship, infrastructure management and financials. On the other hand, one of the most modern and cited studies was that of Osterwalder and Pigneur [22] with the "Business Model Canvas", consisting of a tool for strategic management and a lean visual startup chart for developing business models, including elements describing a firm's or product's value proposition, infrastructure, customers and finances.

\section{How to innovate in business model design?}

Amit and Zott [23] comment that an innovative business model can create a new market or exploit new opportunities in existing markets. This occurs in three points that characterize a company's business model: (1) by adding novel activities (content); (2) by linking activities in novel ways (structure); and (3) by changing one or more of the parties that perform any of the activities (governance).

\section{What is a sustainable business model?}

This study is directly related to a sustainable business model. Schaltegger et al. [24] define a business case for sustainability as the one which has the "purpose to and does realize economic success through (not just with) an intelligent design of voluntary environmental and social activities". Furthermore, this model should meet three requirements: (1) voluntary activity with the intention to contribute to the solution of societal or environmental problems; (2) create a positive business effect, and (3) a certain management activity has led or will lead to the intended socio-economic or environmental effects. Lüdeke-Freund [25] asserts that a sustainable business model creates a competitive advantage through superior customer value contributing to a sustainable development of society and the company itself. According to Stubbs and Cocklin [26], "organizations will only be sustainable if the dominant neoclassical model of the firm is transformed, rather than supplemented, by social and environmental priorities". One of the most relevant studies investigating sustainability in business models is that of Bocken et al. [27-29], who affirmed that sustainable business models must be economically sustainable as a prerequisite, while these go beyond delivering economic value and include a consideration of other forms of value for a broader range of stakeholders. Bocken et al. developed a "value mapping tool" (Figure 1) in order to "assist in providing a systemic approach to the generation of new business model ideas for sustainability that uses a multi-stakeholder perspective and explores both positive and negative forms of value creation". This tool helps users to understand aspects of value in a network of stakeholders and identify conflicting values and opportunities for business model redesign.

Regarding mobility (including the automotive industry), Wells [30] warned that there is an "urgent need to understand more clearly the scope and barriers to growth afforded by business model innovation, both in the automotive industry and more widely_particularly with respect to sustainability". The 
following section illustrates four notable cases from the automotive industry regarding sustainable mobility, remarking upon their more relevant business model aspects which may have much in common with the business model.

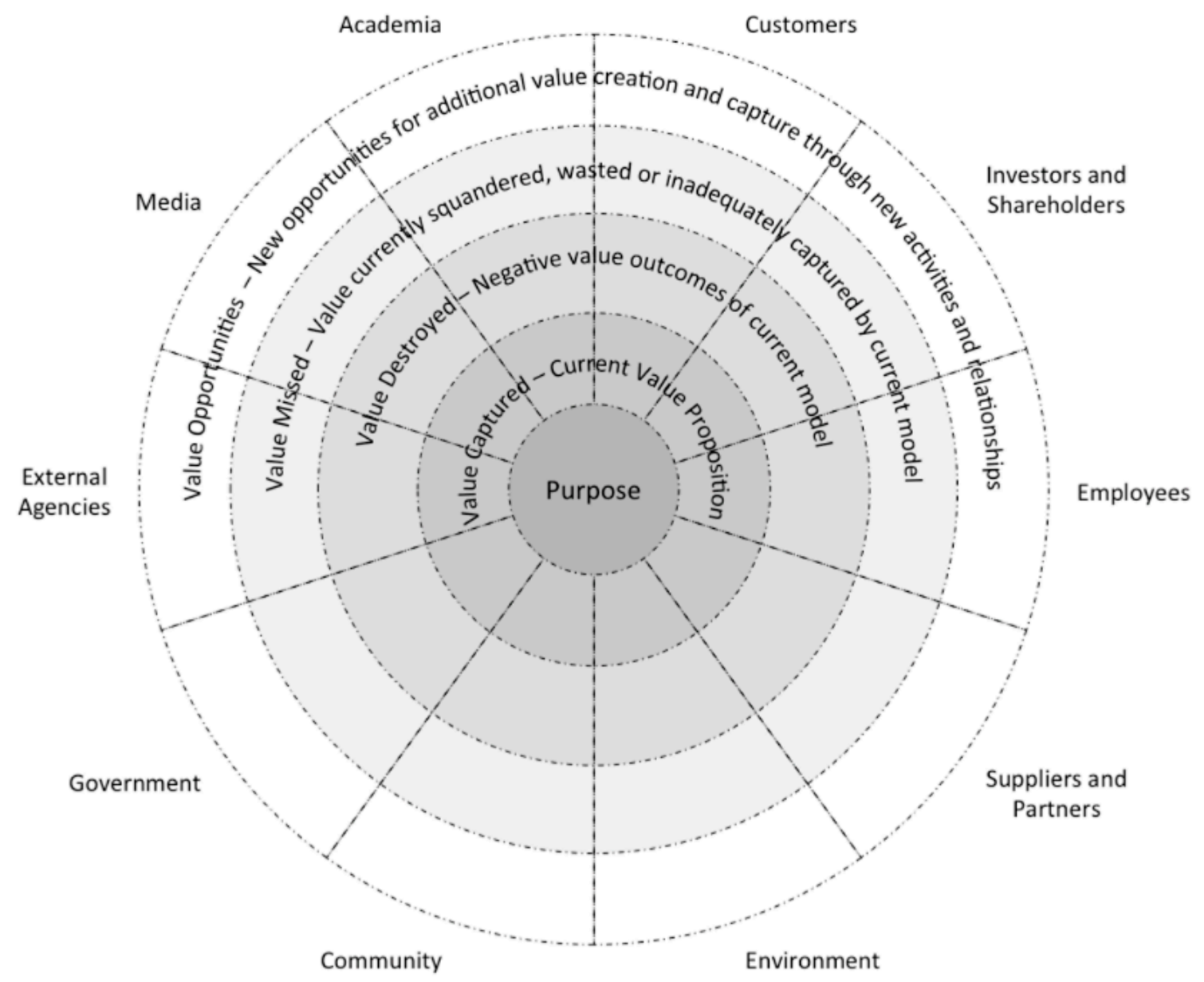

Figure 1. Value mapping tool [27].

\subsection{Practice Cases Integrating Sustainable Business Models into Mobility}

Public funding is perfectly suitable for sustainable business models of transportation. Nuride [31] is a web-based ridesharing network which rewards participants with points that can be traded for sustainable rewards (Figure 2) like discounts, free tickets and gift cards from numerous corporate sponsors. They believe that the most efficient way to reduce traffic congestion and to clean the air is for people to share rides. The service is available in the United States and receives funding from the government but also from corporate sponsors who pay Nuride according to the number of trips taken that pass their outlets, while others simply use a formula according to their sales through Nuride.

Regarding the behavior of Nuride's users [32], incentives go a long way to getting people to change their behavior. They claim that they have not received complaints and that their community takes care of itself, while the main value proposition is to save people money by getting people to save money.

- $58 \%$ of users joined because of the rewards and $48 \%$ drove to work alone.

- $\quad 75 \%$ reported a successful rideshare match, $83 \%$ share rides "more" or "much more", $56 \%$ of active members have been active more than one year and $60 \%$ redeemed a reward. 
- Rewards are the key for loyalty, which implies a bigger database, more matches, increased referrals and valuable feedback.

- Ongoing (not one-time) sustainable, good and local rewards generated more trips than poor local rewards.

- To date it has metered the following data: 345,754 tons of emissions prevented, 126,253 members, $35,181,935$ gallons of gasoline saved, $\$ 407,053,137$ saved, 35,049,453 greener trips and $16,487,448$ shared trips, among other data.

\section{Sustainable rewards are sponsored - not purchased}

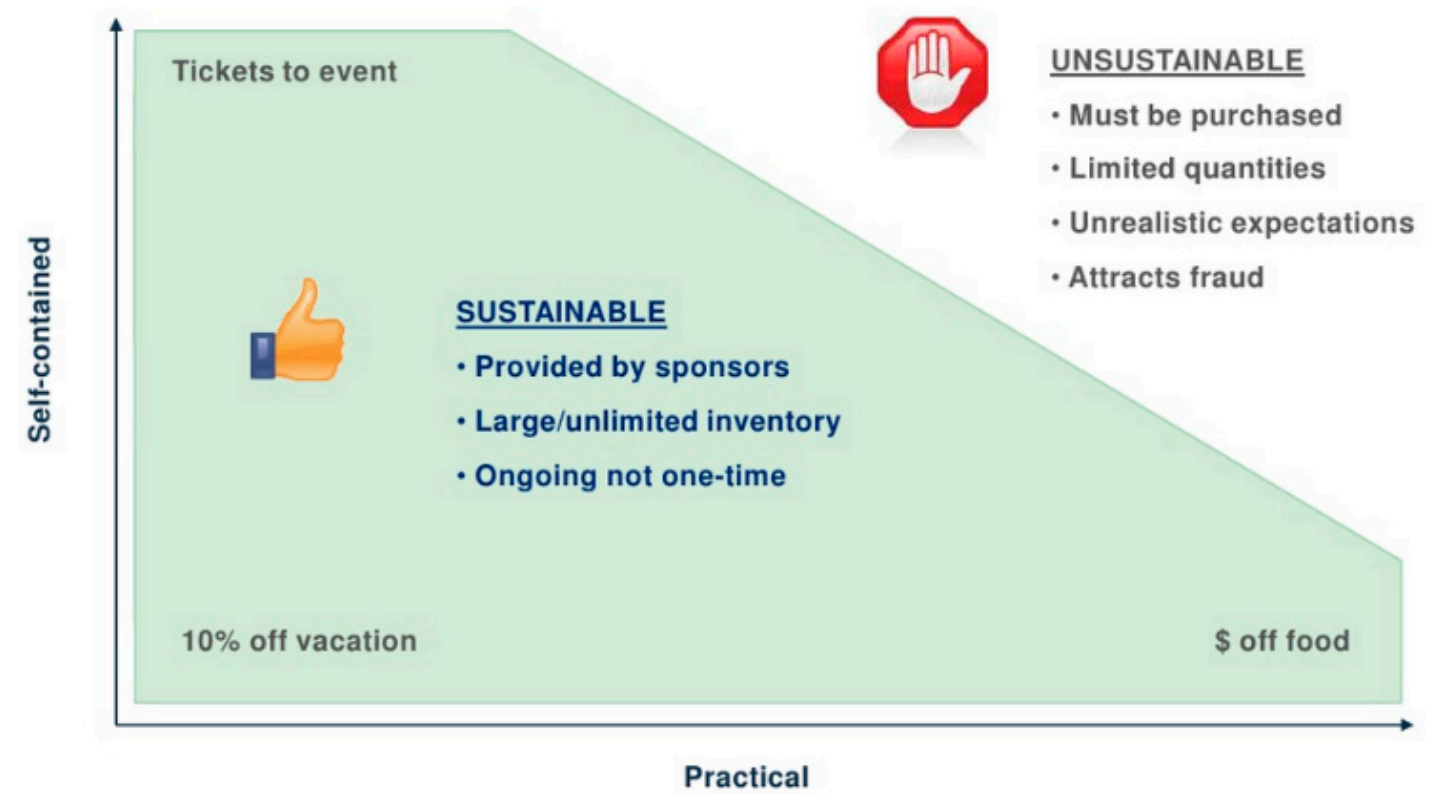

Figure 2. Nuride's sustainability based on rewards [32].

Nevertheless, the solution lacks the necessary technological background to validate whether a trip took place or not. In other words, the good faith of users is the only consideration, and therefore it is perfectly possible to cheat the system with non-existing trips and receive the rewards. This particular practice case has described how a project of sustainable mobility becomes successful by implementing a rewards-based mechanism for economy stimulation.

The concept multimodal transportation is one of the most popular strategies for sustainable mobility due to the fact that it is possible to integrate the network of the existing transportation providers into a single solution. RouteRANK [33] provides door-to-door, multimodal and multicriteria travel planning. It addresses the entire travel route by integrating rail, road and air connections in order to find the best possible travel routes, allowing users to sort them according to their particular priorities such as price, travel time and $\mathrm{CO}_{2}$ emissions.

$\mathrm{CO}_{2}$ emission calculations are based on a model developed by the IFEU Heidelberg. They are further refined using information from the European Commission, non-profit organizations, transport providers and universities across Europe. There is a (free) public solution with limited functionalities and two (standard or customized) commercial solutions with advanced features. Figure 3 compares these three solutions. 


\begin{tabular}{|c|c|c|c|}
\hline Version & Custom developed & Standard professional & Public \\
\hline \multicolumn{4}{|l|}{ Layout and usage } \\
\hline Branding & any branding & routeRANK & routeRANK \\
\hline Commercial use & yes & yes & no \\
\hline Unlimited searches & yes & yes & no \\
\hline Ads-free & yes [1] & yes & no \\
\hline Account management & yes [1] & yes & no \\
\hline \multicolumn{4}{|l|}{ Search parameters \& criteria } \\
\hline Search scope & custom & expanded & standard \\
\hline Schedule and fare data & any available interface & standard & standard \\
\hline Price, duration, $\mathrm{CO}_{2}$ & yes [1] & yes & yes \\
\hline Work time/productivity & yes [1] & yes & no \\
\hline Risks assessment & yes & no & no \\
\hline Additional locations [2] & yes & no & no \\
\hline \multicolumn{4}{|l|}{ Features } \\
\hline Results filters & all criteria [1] & all criteria & airport and time \\
\hline Additional car types & taxi \& rental $[1]$ & taxi \& rental & taxi \\
\hline Car customization & yes [1] & yes & yes \\
\hline Train customization $(1 / 2$, etc. $)$ & yes [1] & yes & no \\
\hline Customized results ranking & yes [1] & yes & no \\
\hline Multiple travelers & yes & yes & no \\
\hline Additional features[3] & yes & no & no \\
\hline
\end{tabular}

[1] Customizable

[2] Additional locations such as villages, stations, points of interest or event location and street addresses.

[3] Additional features such as map illustration, street address search precision (door-to-door), API-access,

Figure 3. Comparison between the RouteRANK solutions [33].

The target group that makes the most use of their service is corporate customers [34]. Companies such as WWF (with "WWF Travel Helper") or the BCD Travel Corporation adopted this system. With respect to behavior, Davidson [35] analyzed survey results from a questionnaire designed to learn more about human behavior in researching travel options. Following this, he decided on the assumptions which best describe this human behavior and automated the collection of data which compare routeRANK's and simulated human optimum routes, for a variety of different user types and for three different optimization criteria (price, journey time and price \& cost of offsetting associated carbon emissions), using a modified version of the system. Finally, the data was analyzed and collected using linear regression and weighted least squares model fitting. This study concluded that by using the solution the average travel planner could save $2 \frac{1}{2}$ hours in research time as well as an important amount of the journey price. Furthermore, a travel planner who researches his journey himself could stand to pay $60 \%$ more than the optimal price. RouteRANK is an example of a successful solution of multimodal transportation, receiving numerous awards regarding its sustainability and business model, in which entrepreneurship and contribution to the environment work in tandem. 
Electro mobility and carsharing are one of the strategies with most support by industrial leaders, policy makers and by the citizenship. Autolib' [36,37] is an all-electric carsharing program launched in 2011 initially formed by the City of Paris and Bolloré, a French holding company and supplier of a small, 160-mile range electric vehicle called the "Bluecar". The service originally consisted of 2200 cars and 4300 charging stations deployed throughout Paris. In a little over two years, approximately 120,000 unique users have logged a total amount of 3.5 million rentals and 18 million miles - all within the limits of a 40 square mile city. Assuming that many of the drivers had never been in an electric car before, these are very significant numbers, contributing to the uptake of EVs in Paris area by offering high visibility and "normalizing" the use of the technology. Furthermore, in order to help facilitate the deployment of charging infrastructure, the City of Paris invested $€ 35$ million and designated a number of parking spaces (Figure 4) for Autolib'.

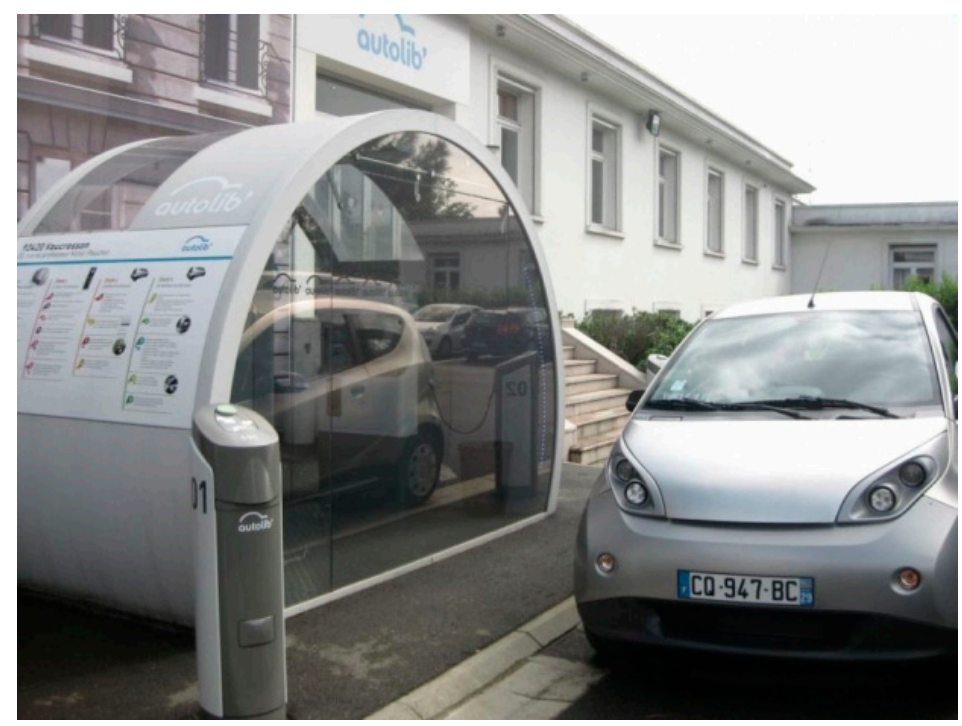

Figure 4. Parking space with a registration kiosk, a charging station and a Bluecar [38].

The service is available to anyone aged 18 or older with a valid French driving license, or a valid foreign license plus the international driving license, who takes out a paid subscription. Each Bluecar has on-board GPS capabilities and can be tracked by the system's operations center. Autolib' charges a variable rate for each half an hour of use, but billing for each rental is calculated on a pro rata basis. In addition, it provides charging services for private owners of electric cars; each additional half-hour costs $€ 6$ for cars and is limited to two times per day. When subscribed (this can be done online or in registration kiosks near charging stations), a car can be reserved with an App, and the charging station is used with a Radio Frequency IDentification (RFID) card obtained right after registration in the kiosk. Weiller [39] claims that the Autolib' business model of public car-sharing has a strong value proposition to customers in terms of cost savings relative to vehicle ownership. However, the main benefits from the service are in the ICT functionalities that significantly enhance the value proposition. To name just two, (1) the GPS in Bluecars allow users to locate all Autolib' stations including the nearest ones, with information on how many vehicles and parking spaces are available; and (2) in-vehicle equipment provides precise information on the state-of-charge (level) of the battery in the car and on the equivalent time and distance left. A major innovation in this business model is the risk distribution that is shifted from the end-user to the company and the municipality. 
Kouwenhoven et al. [40] conducted a study in order to estimate the potential demand for Autolib', as a new transport system for Paris, including surveys on citizens' behavior to predict whether the solution could work or not. One of their conclusions stated that they cannot give any guarantees that the potential market forecasts will in fact become a reality in the future. Nevertheless, to date the system has succeeded and is even expanding to Lyon and Bourdeaux, while deals have been signed to begin operating offshoots in London and Indianapolis in 2015 as future plans for expansion.

$\mathrm{CO}_{2}$ emissions metering and the enhancement the awareness of sustainable mobility practices in order to become greener using an App, are the goals of Commute greener [41], which is a mobile-based application developed by the Volvo Group. The app transforms a cell phone into a tool for measuring emissions generated during every day commuting, including traveling by bus, car, train, bicycle or other means of transport. Users include corporations, cities, organizations and individuals. The program challenges users to reduce carbon emissions and traffic congestion while improving health and quality of life. It also calculates financial savings and gives proactive suggestions on how to Commute Greener, such as riding on public transport or taking a bus. In addition, it provides a community website where commuters can challenge each other to reduce their individual carbon footprint. The inherent business model is based on the work of Bocken [42] with the "win-win-win sustainable business model" that creates advantages for at least three different groups, for example manufacturers, retailers and consumers, while positively contributing to the environment and society [43] (Figure 5):

- Citizens generate good feeling with actions, gaining recognition and stimulating changes.

- Organizations develop better teamwork, improve brand and business recognition, and gain and use time wisely.

- $\quad$ Society makes effective use of sustainable transports while reducing $\mathrm{CO}_{2}$ emissions.

Commute Greener is an excellent example of how a theoretical sustainable business model-the "win-win-win" proposed by Bocken [42]—is integrated into real implementation.

\section{Value network to Commute Greener!}

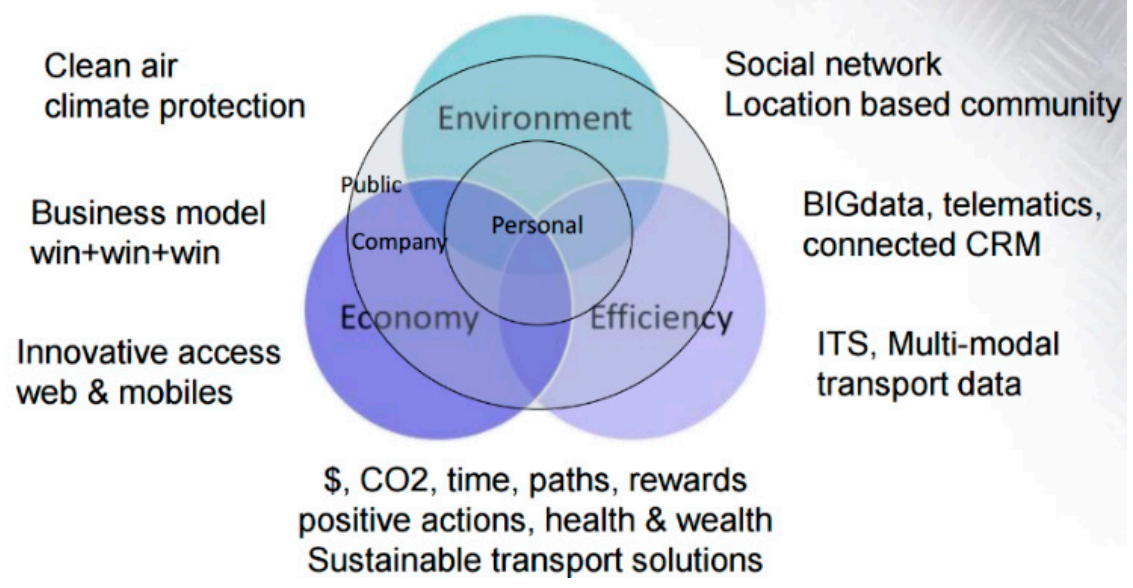

Figure 5. Key aspects of the Commute Greener business model [43]. 


\subsection{Development of the Incentivized Sustainable Mobility Conceptual Business Model}

Following the methodology, this section will describe the Incentivized Sustainable Mobility Conceptual Business Model, built considering the previous literature and practice cases.

The Incentivized Sustainable Mobility is a conceptual sustainable business model of transportation in which four stakeholders - citizens, commerce, mobility services and public administration - cooperate in order to enhance individual (and global) socio-economic and environmental development, by metering the carbon footprint of the technologically-validated sustainable mobility practices, rewarding equivalently these with discounts coupons to be exchanged in the associated commerce.

This definition indicates that the business model is owned by the public administration in the context of Smart Cities [44], with the citizen as key stakeholder. It is essentially aimed at being "non-profit", although it is flexible enough to integrate additional classic methods for monetizing in order to become economically sustainable, which is desirable as suggested by Bocken [27]. Figure 6 describes its life cycle.

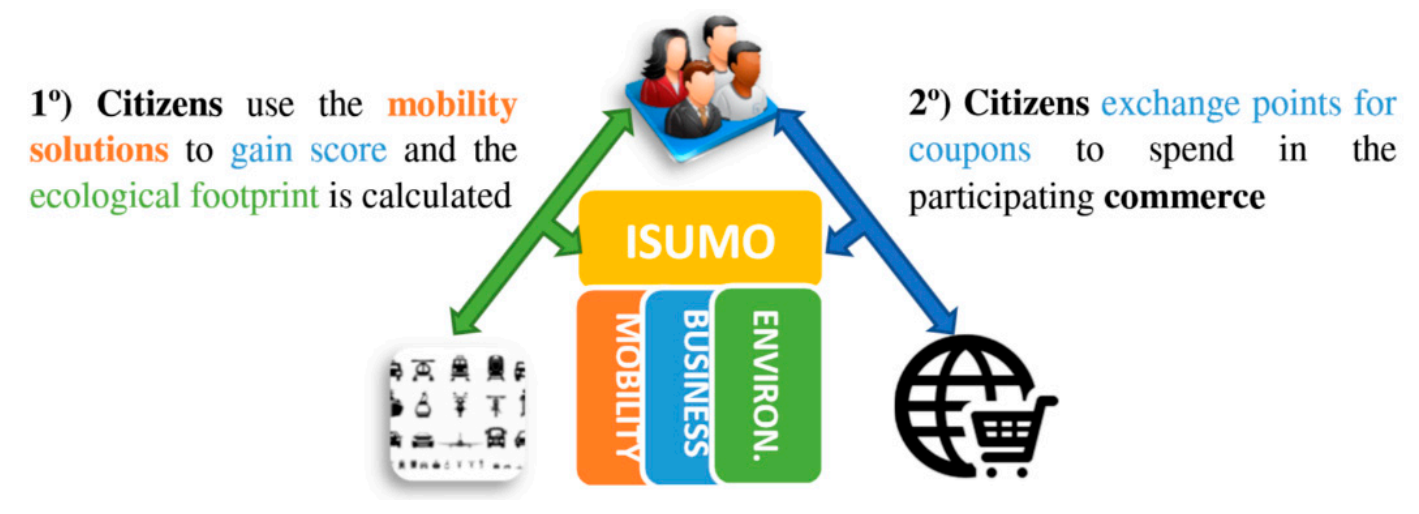

Figure 6. Life cycle of the ISUMO business model.

There are three fundamental principles that support the business model.

\section{(1) Rewards and ICTs as key value propositions}

The business model builds on the importance of being web-based and with rewards for reducing $\mathrm{CO}_{2}$ emissions through implementing sustainable mobility practices, as a direct value proposition for the customers but also including indirectly the rest of the stakeholders. In this context, the previous literature examined by Rappa [20] showed a hybrid model which combines e-commerce and the Infomediary Model with Incentive Marketing, as "a customer loyalty program that provides incentives to customers such as redeemable points or coupons for purchasing from associated retailers". Such loyalty has been effectively demonstrated in the practice cases of Nuride and Commute Greener. However, this model gives more importance to the figure of the commercial stakeholder who have their own virtual panel for management of the promotions offered to citizens, following up their marketing data (dates of coupons created, exchanged and by whom) and validation of the QR-coupons. For instance, the technological platform (ISUMO) provides a free client-server App with a QR scanner for validating the QR-coupons with ease.

There is an improvement here regarding gaining scores. As the definition of the business model suggests - "technologically-validated"- the business model does not just believe in the good faith of users as occurs in the case of Nuride, or in the case of Commute Greener in which it is possible to gain 
points by simply selecting "work from home". This business model has explicit features to validate whether a certain practice of sustainable mobility effectively took place. This is possible with an App and Smartphone (with GPS and plan data or WIFI functionalities) that allows citizens to voluntary geotrack (with guarantees of confidentiality) their trips, providing a trustworthy solution for municipalities as well.

\section{(2) High level of innovation}

This business model intends to provide a high level of innovation implicating every stakeholder in achieving not only individual goals but global ones. This level of innovation is described by the authors Amit and Zott [23], and implies (1) adding novel activities (content); (2) linking activities in novel ways (structure); and (3) changing one or more parties that perform any of the activities (governance). This is detailed in the next figure, for the business case (Figure 7).

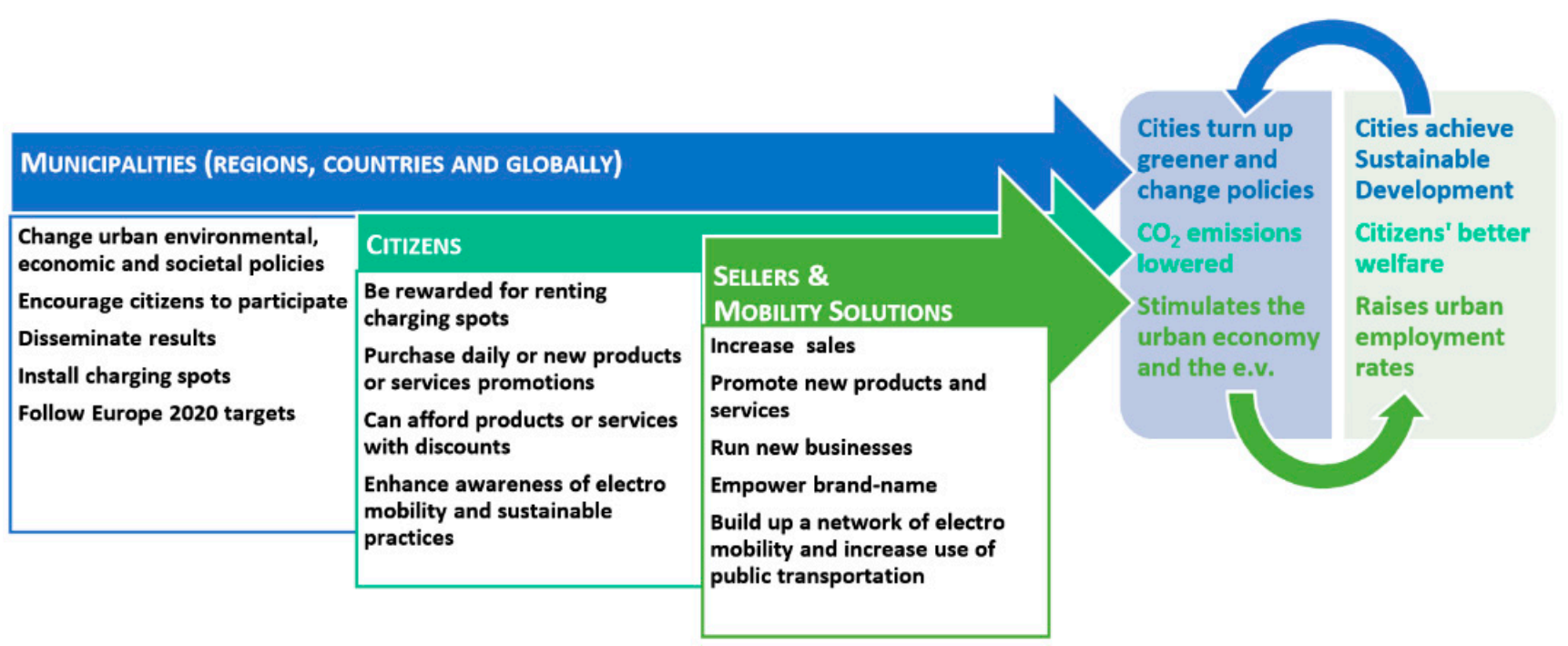

Figure 7. Innovation aspects of the business model.

The technological solution that gives support to this business model (ISUMO) is what makes possible its high level of innovation, including improvements and features from the solutions mentioned previously.

(1) Rewards: technical validation of each trip and specific App and tools for sellers to manage promotions and follow-up their marketing results.

(2) Multi-modal transportation search: unrestricted features for public use with no limitation to any network of mobility providers, so any ICT of transportation can join.

(3) $\mathrm{CO}_{2}$ emissions metering: carbon footprint calculated and saved in the citizens' account, but also calculated for the municipalities or regions that citizens belong to (routeRANK did not allow to create a user account in order to store and manage this information).

(4) Innovation in electro mobility (Table 2): the network of low-cost charging spots does not require additional infrastructure to register (Autolib' kiosk), nor an RFID card to use the charging spot Only a Smartphone is needed with capabilities to display a QR code (or this could be printed on paper). The reasons for choosing $\mathrm{QR}$ codes both for coupons and for using the charging spots are: (1) 2 billion consumers worldwide will have a Smartphone by 2016 [45]; (2) QR are very 
popular, for example in Spain [46]; (3) the patented charging low-cost spots do not require payment or telecommunication parts that would be necessary using methods such as credit cards, that would make the device much less economically feasible and introduce new problems to solve. These would include privacy, security, complexity or availability depending on telecommunications, far from what the device was patented for. Near-Field Communication (NFC) is an attractive technology but still not implemented widely enough and it requires mid to high-end Smartphones, thus for the moment being less accessible to the citizens.

Table 2. Features of practice cases used by the business model.

\begin{tabular}{cccccc}
\hline Feature & ISUMO & Nuride & RouteRANK & AutoLib' & Commute Greener \\
\hline Rewards & $\mathbf{X}$ & $\mathrm{X}$ & & & $\mathrm{X}$ \\
Multi-modal transportation search & $\mathbf{X}$ & & $\mathrm{X}$ & & \\
$\mathrm{CO}_{2}$ emissions metering & $\mathbf{X}$ & $\mathrm{X}$ & $\mathrm{X}$ & $\mathrm{X}$ & $\mathrm{X}$ \\
Innovation in electro mobility & $\mathbf{X}$ & & & $\mathrm{X}$ & \\
\hline
\end{tabular}

\section{(3) Sustainability in transportation}

The business model supports the work of Bocken et al. [27-29], one of whose main aims is the reduction of $\mathrm{CO}_{2}$ emissions. It makes use of the existing sustainable mobility solutions, but also to build up the necessary network of low-cost charging spots for the upcoming electric vehicle, which in turn impacts on air quality. As a result, the stakeholders enhance awareness of sustainable mobility solutions and become more conscientious concerning their mobility practices in order to minimize their consequent carbon footprint. Municipalities that support this business model modernize and obtain greener certifications, but the urban economy also becomes more sustainable overall by stimulating consumption and changing citizens' behavior through the use of coupons in participating businesses, with possibilities to create new job positions according to the "Europe 2020" headline objectives. The resulting behavior should result in a new consumption pattern of "coupons culture" with a background of sustainable mobility implying the reduction of $\mathrm{CO}_{2}$ emissions. Finally, this business model (which is essentially "non-profit") makes it possible to become economically sustainable if additional mature methods for monetizing - such as advertising, premium services, monthly membership - are included, although initially this was not intended due to the low costs expected (mainly, server and development).

\subsection{Description of the Incentivized Sustainable Mobility Conceptual Business Model}

There are various methods for describing a business model, as mentioned previously. The one presented by Dobosson-Torbay et al. [21] is perfectly valid for e-business, however it is sufficiently not up to date for the requirements of this study. Bocken [27] also introduced the value mapping tool which can focus excellently on sustainability and multi-stakeholders, but "Business Model Canvas" (Figure 8) by Osterwalder and Pigneur [22] is a widely known tool relatively easy for understanding ideas.

The colors mean the level of importance or relevance, where red is the most important level followed by orange and yellow. This business model is related to Smart Cities [44], being essentially owned by public administration, to enhance performance and wellbeing, to reduce costs and resource consumption, and to engage more effectively and actively, placing emphasis on citizen engagement. It is important to 
note that the revenue streams are optional, the municipality should consider whether the cost structure is assumable or not. Key activities which are fundamental to guaranteeing the success of the platform include: (1) reaching agreements with as many ICTs of mobility as possible in order to integrate them into the multimodal service; (2) collaborating with numerous businesses that could offer a sufficient variety of discount coupons to the citizens, and (3) stimulating the interest of charging spot providers in order to purchase low-cost charging devices, aiding growth of the required support network for the electric vehicle.

The next section explains the ISUMO platform and modules that support the conceptual business model, and describes a real implementation named the Recarga Jaen project which integrates the solution partially in the municipality of Jaen.

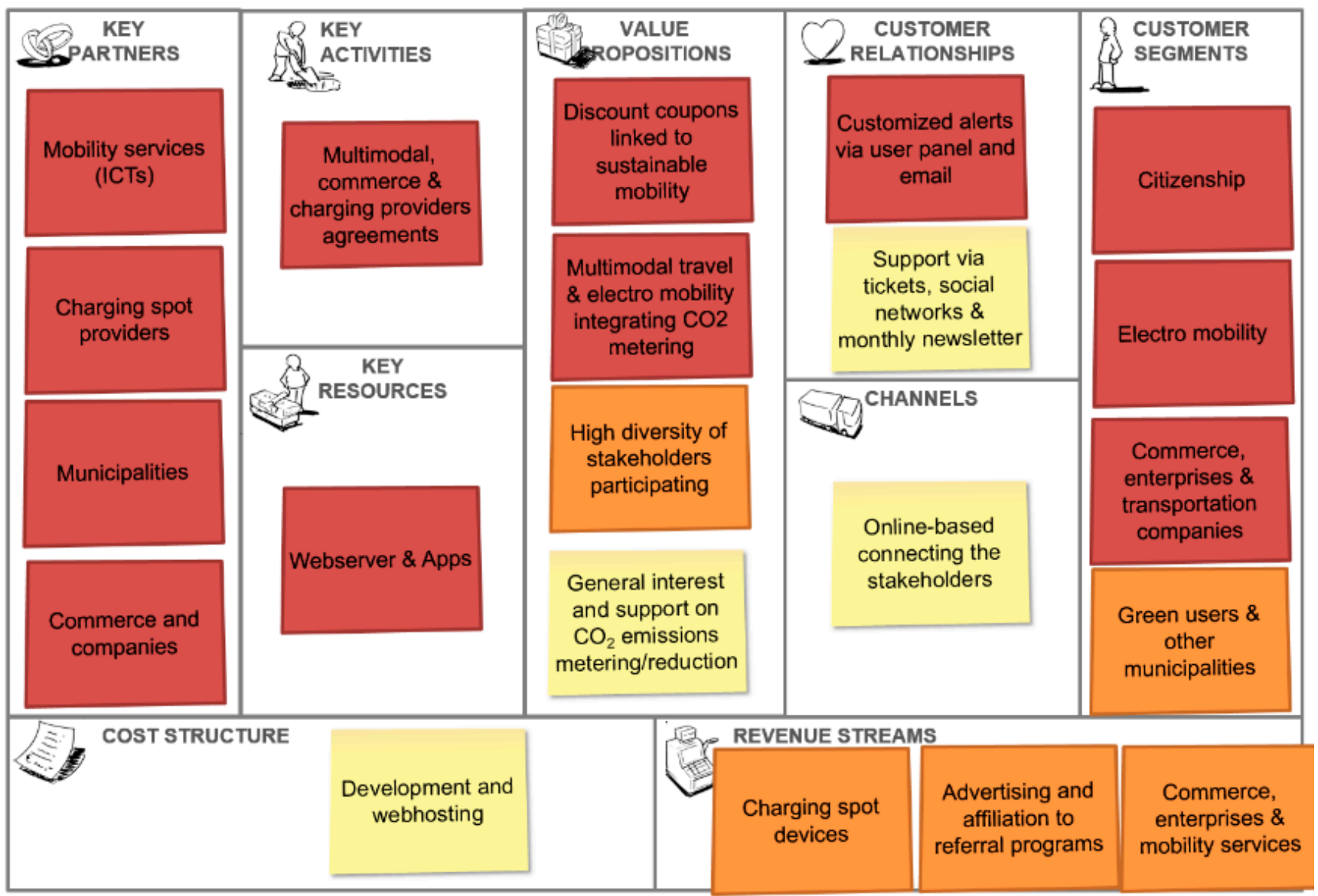

Figure 8. Business model canvas.

\section{Architecture}

The technological implementation of the conceptual business model integrates a set of meta-services that support transportation and electro-mobility processes and meet the Europe 2020 targets on $\mathrm{CO}_{2}$ reduction, economic stimulation and increase of general welfare. The current section describes the model architecture composed of three modules and four sub-modules (Figure 9). The next sections, Sections 3.1-3.3, describe these modules. Section 3.4 presents the graphical interface available to the user, and Section 3.5 includes real and partial implementation of the solution. 


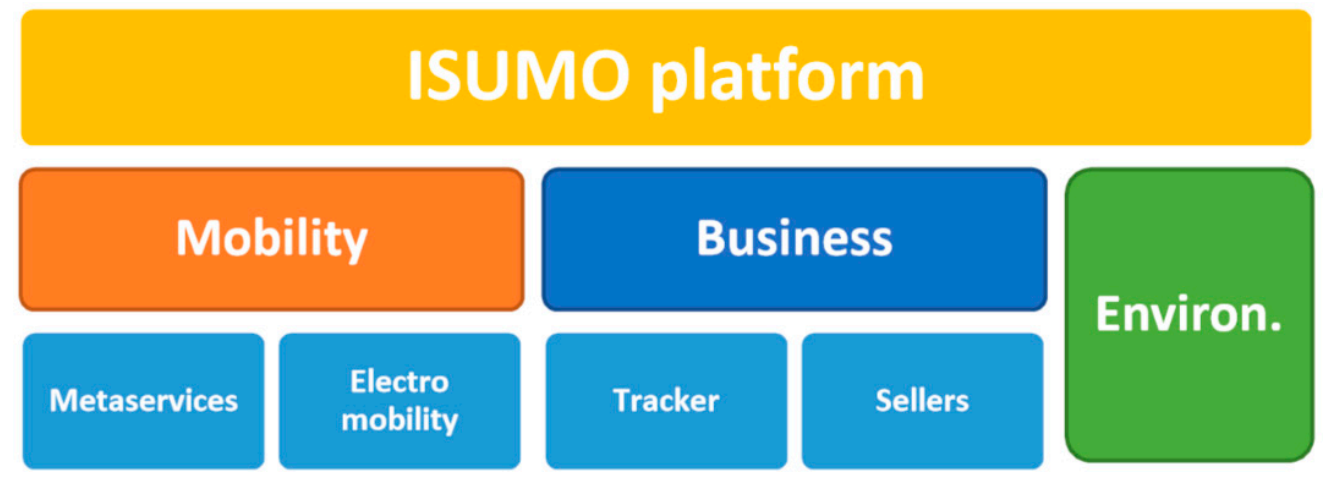

Figure 9. The ISUMO platform's modules and sub-modules.

\subsection{Mobility Module}

The mobility module in Figure 9 integrates a GIS with the metaservices and electro-mobility sub modules and contains the primary user frontend and administration backend. It implements multi-platform Responsive Web Design (RWD) user experience.

This module incorporates a community as the meeting point where the stakeholders cooperate, share and gain knowledge as they practice Education for Sustainable Development (ESD), practices and policies that should move into societal, policy and research arenas with high visibility and traction [47]. The community is the virtual space where citizens can participate in the forum, share experiences in social networks, contact and receive support from the platform's representatives, learn sustainable practices and take action on challenges proposed by municipalities in the forum. Sellers and mobility services can advertise - free of charge - their promotions, products or services, but can also provide support to their customers. Municipalities can create or organize challenges, disseminate results such as changes in their policies, or announce their $\mathrm{CO}_{2}$ emissions savings.

\subsubsection{Metaservices Sub-Module}

This meta-services sub-module rewards the use of existing transportation ICTs and provides an integrated view and access to the vast and highly diversified network of mobility solutions including different websites, technologies, methods to use, compatibility with certain operating systems, devices and web browsers (Figure 10). Without this solution, citizens are forced to (1) previously know which are the existing ICTs of public transportation; (2) learn how to use each technology; (3) own a specific device; (4) install certain software (such as a web browser or Operating System); and (5) search (and eventually, register) for the existing transportation providers' websites (and sections), one by one. The metaservices solution integrates into a single GIS the widest possible network of transportation ICTs (similar to routeRANK) for ease of use and compatibility, multiplying the number of trip choices and travel time flexibility, and increases travel-time reliability by multiplying the choices for planning an intermodal trip and ultimately, directly inferring user satisfaction $[8,9]$. 

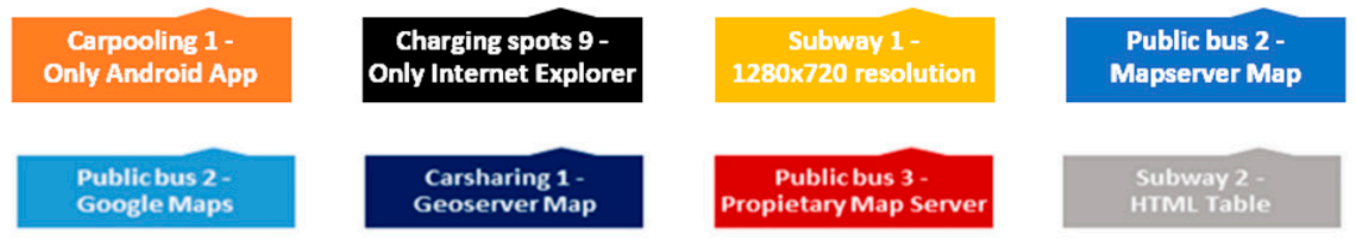

Carpooling 2 -

Figure 10. Overview of the existing widely dispersed and heterogeneous network of providers and various technologies available to access the information.

Data feeds provided by the transport providers are integrated into a single GIS-based system. Therefore, when the citizens set search preferences criteria a meta-crawler visits and extracts providers' data feeds to define a set of rules for encoding documents in order to translate the data into the map (Figure 11).
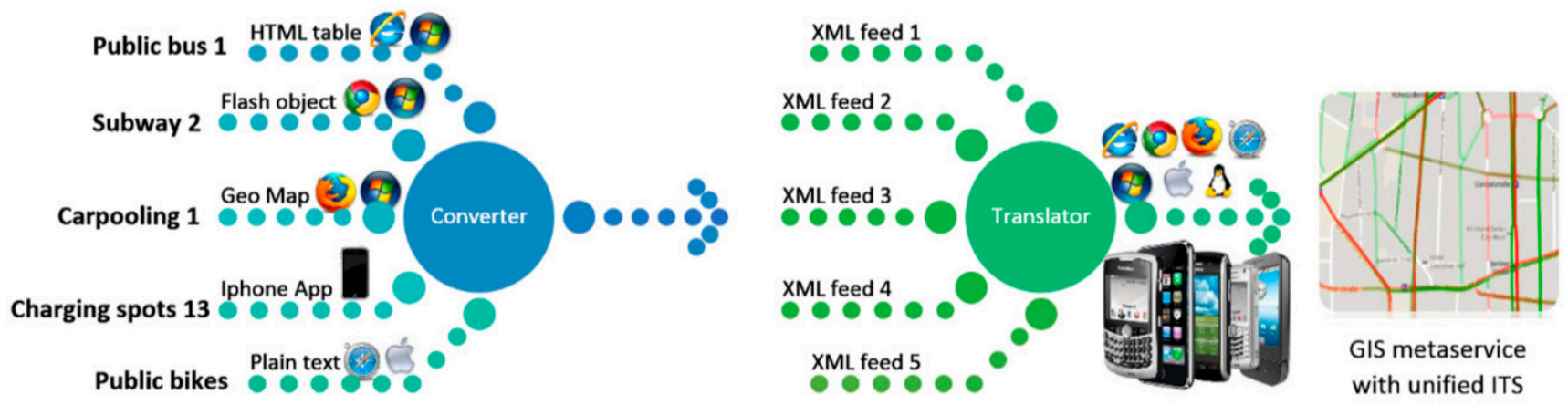

Figure 11. Meta-services unifies the heterogeneous network of ICTs of transport into a GIS.

Citizens access the GIS in order to plan a trip combining various transportation methods. However, it is important to note that this solution does not geotrack any trip information, due to the fact that this processing is carried out by the Business module which will finally grant the score. There are two stages, detailed as follows (Figure 11):

(1) Converter: generates a friendly and defined ISUMO data feed from each existing ICT dataset. These data feeds follow two methods:

(a) If the provider implements an Application Programming Interface (API) to access their data, the converter needs to implement algorithms which filter the API's useful information and generate a feed with the ISUMO feed. This scenario is adequate since it requires medium human resources for programming the converter.

(b) If a provider does not have an API but supports ISUMO with their I.T. resources, then they will generate the ISUMO data definition which does the work of the converter, making this the ideal scenario.

(c) If not, there are two options for generating the data definition:

(i) Manually adapt, feed-by-feed, web-crawlers (which visit the services websites) and parsers (which are selective with the data accesses, such as meta tags). This scenario is costly in terms of human resources. 
(ii) Automated scripts that follow already programmed ones, for example when the same transportation service is given to various regions. This last scenario takes advantage of previous work and integration is more immediate and less costly once it is implemented for one service which is compatible with similar ones.

(2) Translator: represents the ISUMO data feed in the GIS with the type of transport, name, destination, line number and arrival time to a certain stop or station and any other useful information agreed with the provider. The manual insertion of data is also required, such as for the location of stops or stations and colored itineraries.

Collaboration agreements with transportation providers (instead of accessing their web services directly without permission) help ensure reception of their data feeds and its adequate expansion.

\subsubsection{Electro Mobility Sub-Module}

The installation of a physical charging infrastructure is an obvious prerequisite to widely available electric vehicle charging at homes, workplaces or elsewhere [48]. Diffusion of electric vehicles is hampered by their own limitations: a charging system requiring a long time and appropriate infrastructure, high purchase price and limited driving range [49]. Furthermore, the existing commercial charging spot devices are still costly, mostly because they include telecommunications or payment-management parts. These payment methods oblige people to carry cash or credit cards, and learn how to use various technologies - such as NFC or magnetic cards and credit cards — or identification methods that could compromise citizens' privacy. It would be easier to simply use a device with the possibility to present a QR code on its screen (or printed on paper), and consequently this would multiply the number of potential customers through ease of use, number of compatible devices, anonymity and security. A patented small, low-cost and QR-based device and a web-based solution is proposed in order to take advantage of existing infrastructures (Figure 12) close to the road such as phone booths, traffic lights or any other available electric sources.
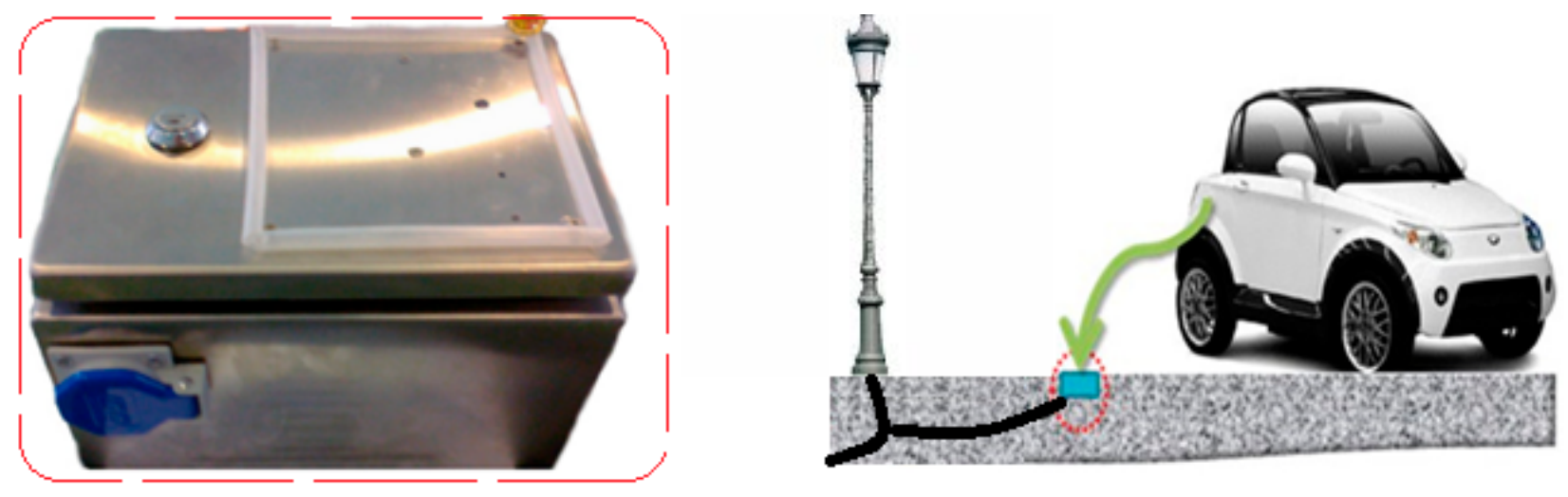

Figure 12. The patented QR-based charging spot and possible application.

The device (named "ISUMO spot") can work isolated from data telecommunications, which includes a (IP 67 compliant) protective cover, and works by reading QR codes presented using low-end devices (not necessarily SmartPhones) or printed on paper. It also does not store or request any personal information (this is managed securely via web) or cash (in order to avoid theft and vandalism). These 
features make it a viable device for electro mobility providers to build up the necessary infrastructure for the upcoming electric vehicles. The ISUMO charging spot provides a very different approach from the aforementioned Autolib' charging station. For instance, Autolib' uses RFID cards which require telecommunications and a larger (and more expensive) infrastructure with components such as the Autolib' kiosk or the charging device itself. The following Table 3 has a summary of the ISUMO spot features.

Table 3. Summary of features of the patented device.

\begin{tabular}{ll}
\hline \multicolumn{1}{c}{ Interface for Rental } & \multicolumn{1}{c}{ GIS and Secure Https Web-Based PayPal Platform } \\
\hline Interface for using the charging spot & Permanent QR reader, 2 LED bulbs and instructions sticker \\
Cost of patented part & From approximately 100€ \\
Cost of the protective cover & Depends on the quality/level of certified protection IP-xx \\
Does it protect from wrong manipulation? & Yes, it has an IP-67 cover and electric protection \\
Does it store personal information or cash? & No, therefore vandalism to extract cash is prevented \\
Can it be hacked using reverse engineering? & No, stored codes are random, the same as the installed in server \\
Type of charge & Any, the electric part is independent of the patented one \\
Does it communicate with any component? & No, so it can work in remote or underground places \\
How to install the device & Plug-and-go, it will boot in one minute after plugging in \\
\hline
\end{tabular}

The electro mobility platform is integrated into the metaservices GIS sub-module with the available ISUMO spots. Citizens decide which spot to rent (this will depend mostly on distance from the spots and price of $\mathrm{kWh}$ set by the provider). After that, they decide for how long the device will be rented (from $30 \mathrm{~min}$ to $8 \mathrm{~h}$ ), and finally purchase the rental via a secure PayPal payments platform, receiving a QR code for one use to scan with the ISUMO spot (this will also be sent with a receipt via email). This sub-module will be explained using a real implementation in Section 3.5., after the necessary business module has been introduced.

\subsection{Business Module}

While the mobility module helps users to adopt practical sustainable mobility solutions, this module is the key to increasing the attractiveness of the platform in order to encourage the stakeholders to use it, resulting in a new consumption pattern of discount coupons linked to sustainable mobility.

The module gets its input from the mobility module, and it is responsible for: (1) tracking sustainable mobility practices, validating them and granting certain scores to citizens; (2) managing the platform for sellers and citizens, who can choose or exchange their points for discount QR-coupons; and (3) validating them using an App for sellers (this is not the same as the App for citizens).

This solution validates the information regarding the platform's mobility solutions implemented by citizens and grants a score depending on how sustainable the practice has been. There is a common mechanism for granting the scores regardless of the mobility solution chosen, the score multiplier - common in computer games - offered as a level-based mechanism to stimulate citizens to continue using the platform for longer periods of time. For instance, level 1 would require 100 points and multiplies the score by $10 \%$, level 2,200 points by $20 \%$, and so on. 


\section{Score calculation for electro mobility solution.}

For each rental of charging spots, the citizen's score is increased as follows.

$$
S=T \times 100
$$

where $S$ (score) is the result of multiplying the $T$ (total price purchased in Euros) $\times 100$.

\subsubsection{Tracker Sub-Module}

Citizens start the ISUMO App for citizens and specify the transportation method being used and geotrack waypoints at the moment of departure and arrival (no intermediate geotracking is required for lower data plan costs). The App connects to the server which compares how realistic the information is for a planned trip by checking the geotracks, type of transportation and timing. Depending on previous data, the business module will grant the score totally, partially $(50 \%$, if the information sent by the citizen is not absolutely trustworthy or incomplete) or deny it (if intended fraud is detected).

\section{Score calculation for metaservices solution.}

As previously commented, Nuride [15] lacks a technological tool for validation that is implemented here as an important part of the business model requirement. This anti-fraud system is a service designed not only to ensure that citizens' sustainable trips take place but also to guarantee the satisfaction of transportation providers, as the usage of their services can be measured and presented. Moreover, in order to obtain greener certifications, municipalities can better demonstrate their carbon footprint.

\subsubsection{Sellers Sub-Module}

This solution is a web platform where citizens can exchange their points for QR-coupons (obtaining also their equivalent string char) and a back-end platform where sellers can manage their promotions in order to: (1) create, modify or remove a promotion; (2) manually check if a coupon is valid to be exchanged - using the platform or the ISUMO App for sellers that instantly scans and validates the coupons; and (3) check stats of coupons created and exchanged, so they can follow up marketing data like the promotions that are working better or which citizens are their top buyers. In addition, the history of transactions with data such as date, product, seller, and price is stored for research.

\subsection{Environment Module}

One of the goals of the platform is to be compliant with the Europe 2020 goal on $\mathrm{CO}_{2}$ emissions reduction. In order to do so, it is critical to raise citizens' awareness towards $\mathrm{CO}_{2}$ emission savings with respect to their mobility patterns. Generally, the environment module consists of a $\mathrm{CO}_{2}$ calculator that observes mobility choices, calculates $\mathrm{CO}_{2}$ emissions and estimates savings and outputs results in a quantitative representation in both tabular and graphical forms.

More specifically, this module monitors relevant mobility data from the platform which are generated, among others, by the mobility and business modules. The use of the most recent available data is a requirement, as all results are expected to be as up-to-date as possible. In order to enable data access and data transfer across the modules, the solution will adopt current best practices and standards regarding interoperability. With these (real time spatio-temporal) data, the module is able to calculate, estimate, 
measure and rank $\mathrm{CO}_{2}$ emissions and savings for distinct levels of granularity with respect to space - from citizen to municipality to region and country - and with respect to time.

In order to calculate the $\mathrm{CO}_{2}$ produced by a journey the model first calculates the distance travelled along the planned route (in the case of the metaservices solution). The total distance is computed by adding up the distance for each small segment of the journey along the network. Depending on the transport type, the model estimates the consumption amount used for travelling the calculated distance.

This computation can use average consumptions per car model. Having the fuel consumption calculated per itinerary it is then possible to estimate the corresponding $\mathrm{CO}_{2}$ production. $\mathrm{CO}_{2}$ production is related to the amount of fuel combusted and the fuel's carbon content (hence, the dependency on fuel type: diesel, gasoline, and natural gas). For electric engines, it is also possible to estimate indirect $\mathrm{CO}_{2}$ production based on the average $\mathrm{CO}_{2}$ production estimates released by energy providers.

(1) Estimates the amount of $\mathrm{CO}_{2}$ emitted per platform's user/time period/geographic area/transport.

(2) Provides estimations, over the same itinerary, with distinct transport types.

(3) Calculates the amount of $\mathrm{CO}_{2}$ emissions and savings (having, as a reference, a specific transport type), as well as the network travelled, providing a map.

(4) Calculates $\mathrm{CO}_{2}$ emissions per geographic area/time period/transport type, determining geographic areas/patterns where $\mathrm{CO}_{2}$ emissions occur. In other words, in (3), the relevant data is calculated for an individual citizen, and this (4) calculates the data regarding the regions or municipalities that the citizen belongs to.

Summarized results of the environmental module are stored in the platform to become available for the front and back office of the platform. Other results such as visual and graphic representations using information visualization techniques are produced based on intermediate results stored in the module. The availability of this data raises the citizen's awareness towards how environmentally efficient their mobility pattern is. Regarding other entities, such as cities and regions, availability of the environmental data is critical for large-scale measurement and planning towards preserving the environment.

\subsection{Use Cases and Graphical Interface}

This section illustrates the ISUMO platform and the underlying business model by describing a use case and how the system is expected to work. Table 4 details a practical case that involves the whole platform's architecture, with a chronogram of novel actions carried out by the citizen and the seller as the main stakeholders of the business model. Each action links to a functionality of the consisting modules or sub-modules of the ISUMO, in order to improve understanding of how the system works.

In Table 4, after each sustainable mobility practice (metaservices or electro mobility), the business module calculates the corresponding score and the environment module measures its carbon footprint. Finally, points are granted and the citizen can exchange them for QR-coupons to present to the seller in order make them effective. Figure 13 depicts a possible graphical interface where the points gained and carbon footprint is estimated, since this is more accurately calculated when citizens geotrack their trips. 
Table 4. Use case which describes how the ISUMO modules and sub-modules are connected.

\begin{tabular}{ll}
\hline \multicolumn{1}{c}{ Action } & \multicolumn{1}{c}{ System Involved } \\
\hline $\begin{array}{l}\text { Citizen does login, organizes a multimodal trip from Madrid } \\
\text { to Paris displaying multiple choices in the GIS. }\end{array}$ & $\begin{array}{l}\text { Mobility module } \\
\text { Metaservices sub-module }\end{array}$ \\
\hline Citizen geotracks (with the ISUMO App for citizens) the start and end of & Tracker sub-module \\
each transportation service This increases the score and calculates its & Business module \\
equivalent $\mathrm{CO}_{2}$ footprint also for the municipality the citizen belongs to. & Environment module \\
\hline $\begin{array}{l}\text { In Paris, the citizen searches (in the GIS) for an ISUMO spot } \\
\text { for charging an electric car. }\end{array}$ & Mobility module \\
\hline $\begin{array}{l}\text { Citizen rents use of the spot (its charging provider receives the income), } \\
\text { obtaining a QR for using the device. Citizen raises his score and updates } \\
\text { carbon footprint (and for the municipality belonged to). }\end{array}$ & Metaservices sub-module \\
\hline
\end{tabular}

The "Pizza Paris" restaurant (seller) previously created discounts using the

seller's panel. Citizen exchanges score for a " $30 \%$ off in pizzas" QR-coupon Sellers sub-module for use in that restaurant.

Seller validates the citizen's QR-coupon (with the ISUMO App for sellers)

and applies the discount to the citizen.

Sellers sub-module

In Table 4, after each sustainable mobility practice (metaservices or electro mobility), the business module calculates the corresponding score and the environment module measures its carbon footprint. Finally, points are granted and the citizen can exchange them for QR-coupons to present to the seller in order to make them effective. Figure 13 depicts a possible graphical interface where the points gained and carbon footprint is estimated, since this is more accurately calculated when citizens geotrack their trips.

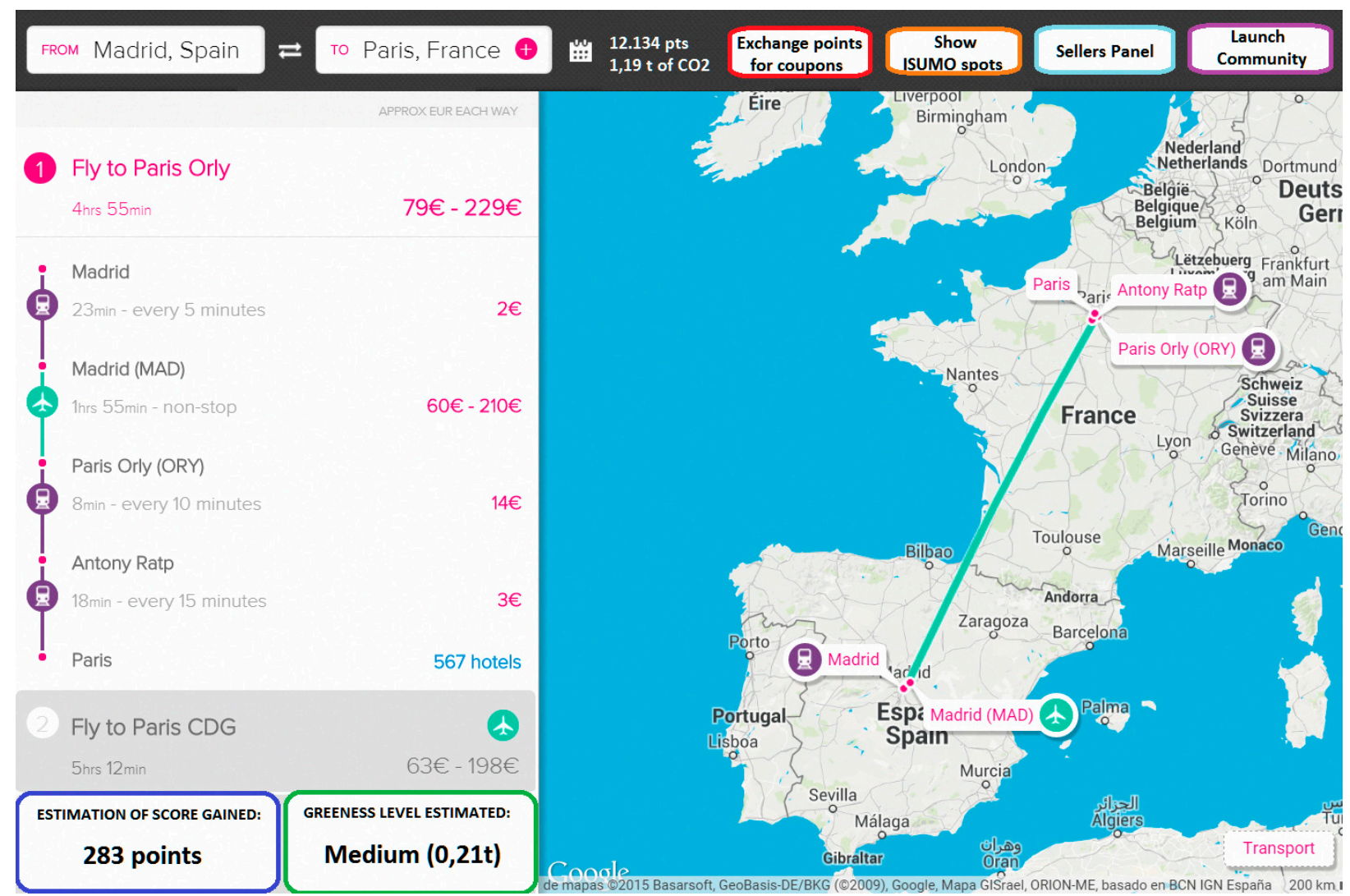

Figure 13. Partial overview of ISUMO's main graphical interface and GIS. 


\subsection{Practical Approach to ISUMO with the "Electro Mobility" and "Sellers" Sub-Modules}

While previous sections describe a conceptual ISUMO idea, this section details a real implementation of the electro mobility sub-module and business module by the University of Jaen, supported by public funding (this appears in the "Acknowledgements" section). The project, named Recarga Jaen, is a real solution which implements the incentivized sustainable mobility business model for the Municipality of Jaen, considering the previously described sub-modules of electro mobility and sellers.

This sub-module uses a web rental system based on Google Maps which shows the available charging spots (using markers) that allow citizens to decide which one is more convenient to rent and for how long. Once the payment has been processed through the PayPal secure platform, the citizen will receive an email (it can also be directly downloaded or printed on paper) with a QR code to be scanned by the device.

Charging spots are composed of three parts: an electronic part (the only patented one), an electric part—separate but integrated with the previous part—and a commercial protective cover. This device includes a covered sticker with device ID, graphic instructions on how to use it and provider's contact information in order to receive customer support if needed.

The electronic part is the core of the QR-based charging spot and is responsible for security, validation (by voice messages and colored LED bulbs) and granting the energy supply to the electric vehicles for a certain period of time. Due to the reduced dimensions of the device, it can also be easily integrated into existing infrastructures such as phone boxes and street lights. It does not require any telecommunication to a web server due to the fact that QR codes are introduced before the moment of installing the device (also in the web server), so it is conceivable to make it work in remote zones isolated from telecommunications (mountains, deserts, ships, underground or touristic areas) and impossible to hack by using reverse engineering because there is no method for generating the codes.

The electric module includes all the necessary protection against possible electric shocks, wrong manipulation and electric connectivity. Currently, it uses the Spanish standard current $(220 \mathrm{~V}, 16 \mathrm{~A})$ and "Schucko" socket compatible with most electric vehicles (from electric wheelchairs and electric bicycles to electric cars), but it is perfectly viable for including fast charging technologies on the electric module due to the separation of the electronic module and the electric charging module. The use of different current specifications for other countries is possible by modifying its charging module.

The commercial cover provides extreme weather conditions (IP-67 certification) protection, but it is possible to use any other materials or technologies (such as fast-prototyping) to build this cover and, as mentioned above, take advantage of the existing infrastructures as a protective cover (in the cases in which its safety and users' safety is guaranteed).

The features mentioned above make the proposed charging spot attractive for commercial use. Installation only requires an electric point and works as a "plug-and-go", which means that anyone can install it without any special technical knowledge, just by connecting the device to the current. Maintenance is based on replacing the QR codes using a micro-SD card, and when these are running low, the web server will send an alert.

Regarding the web platform that supports the charging spot, it is a GIS-based view where citizens can select and rent a charging spot. Figure 14 displays an example of how the view helps citizens decide which spot to rent and for how long (from half an hour to $8 \mathrm{~h}$, with intervals of $30 \mathrm{~min}$ ). 

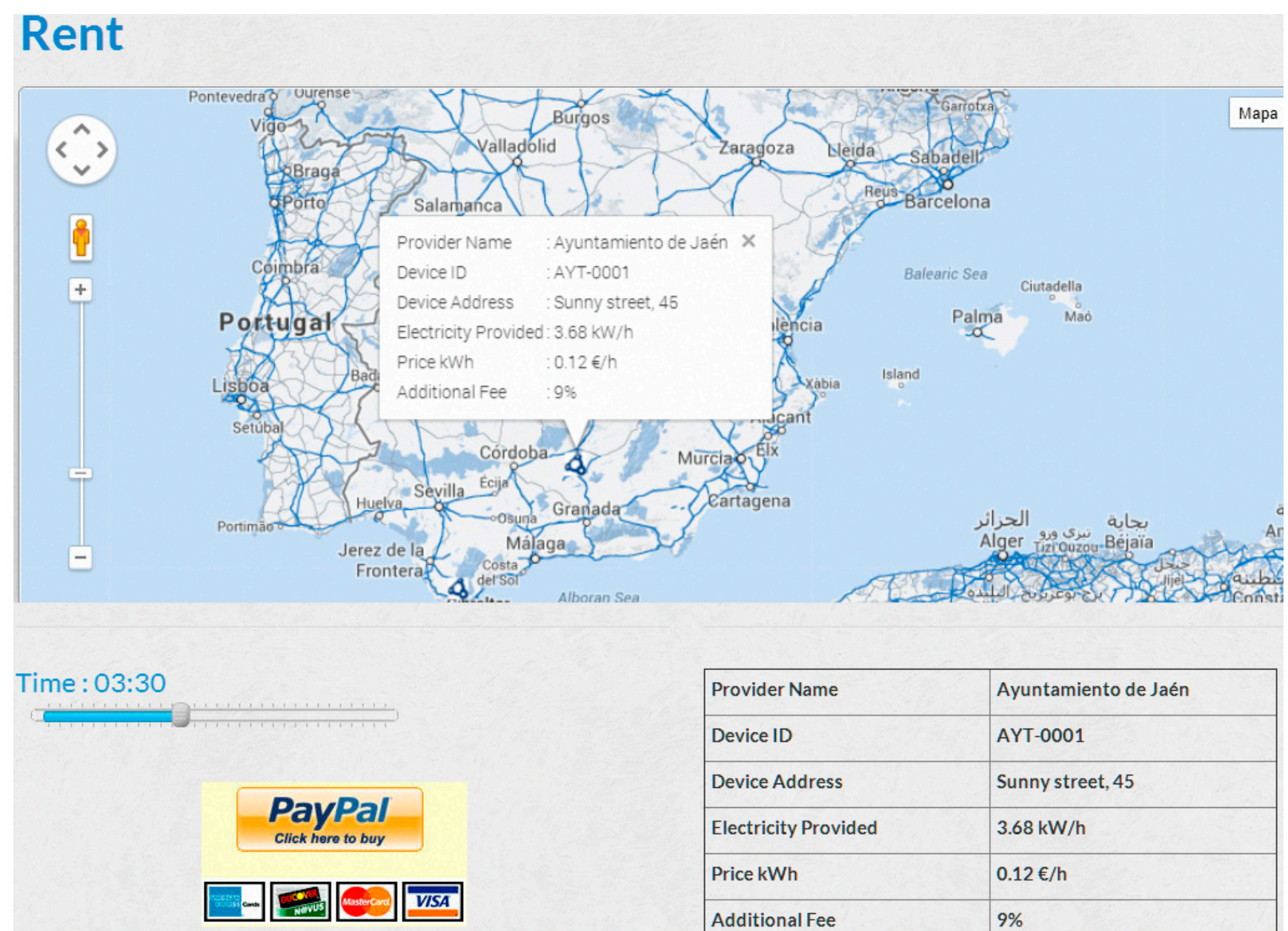

\begin{tabular}{|l|l|}
\hline Provider Name & Ayuntamiento de Jaén \\
\hline Device ID & AYT-0001 \\
\hline Device Address & Sunny street, 45 \\
\hline Electricity Provided & $3.68 \mathrm{~kW} / \mathrm{h}$ \\
\hline Price $\mathrm{kWh}$ & $0.12 € / \mathrm{h}$ \\
\hline Additional Fee & $9 \%$ \\
\hline Price & $1.685 €$ \\
\hline
\end{tabular}

Figure 14. GIS system on Google Maps for selecting the charging spot and rental time.

There are various attributes that make citizens decide among the available charging spots: provider, location, electrical power (also whether the charge will be standard or fast), price of Kilowatts per hour and any additional fee (percentage) that the provider will charge (if agreed as part of the service). The total price is therefore calculated with the following formula:

$$
T=(E \times P \times t) \times F
$$

where $T$ is the total price purchased in Euros, $E$ is the electrical power provided by the device, $t$ is the time rented and $F$ is the additional provider's fee (if applicable). Tests carried out by the University of Jaen (using standard charge) on a Renault Twizzy car showed that a typical charge of $3 \mathrm{~h}$ with an additional fee of $5 \%$ had the following price: $(3.68 \mathrm{kWh} \times 0.099 € / \mathrm{kWh} \times 3 \mathrm{~h}) \times 1.05=1.14 €$.

Once the spot and rental time are selected, the citizen is redirected to a secure online payment platform to confirm the order using credit card or PayPal account, and finally the QR code is generated and also sent to the citizen's registration email for use in the charging spot. The charging spot provider receives the income immediately to the PayPal account provided at the moment of registration. Figure 15 describes the life cycle whereby each stakeholder is related with the platform. 
The charging spot providers have a special role in this case; the project aimed to promote the participation of anyone (individual contractor or enterprise) in an open network of electro mobility for garages, neighborhoods, isolated places, commercial centers or petrol stations, to name a few, as long as they complied with the current legislation regarding electricity or any other relevant legislation. Charging spot providers receive an additional fee (the percentage over the total price) that allows them to amortize their investment and afterwards obtain profits. This fee cannot be abusive and a consensus must be reached with the platform's representatives. The business model of this solution aims in particular to become sustainable, and providers receive income from the platform (Figure 16), unlike the transportation providers and sellers who obtain it directly from the citizens.

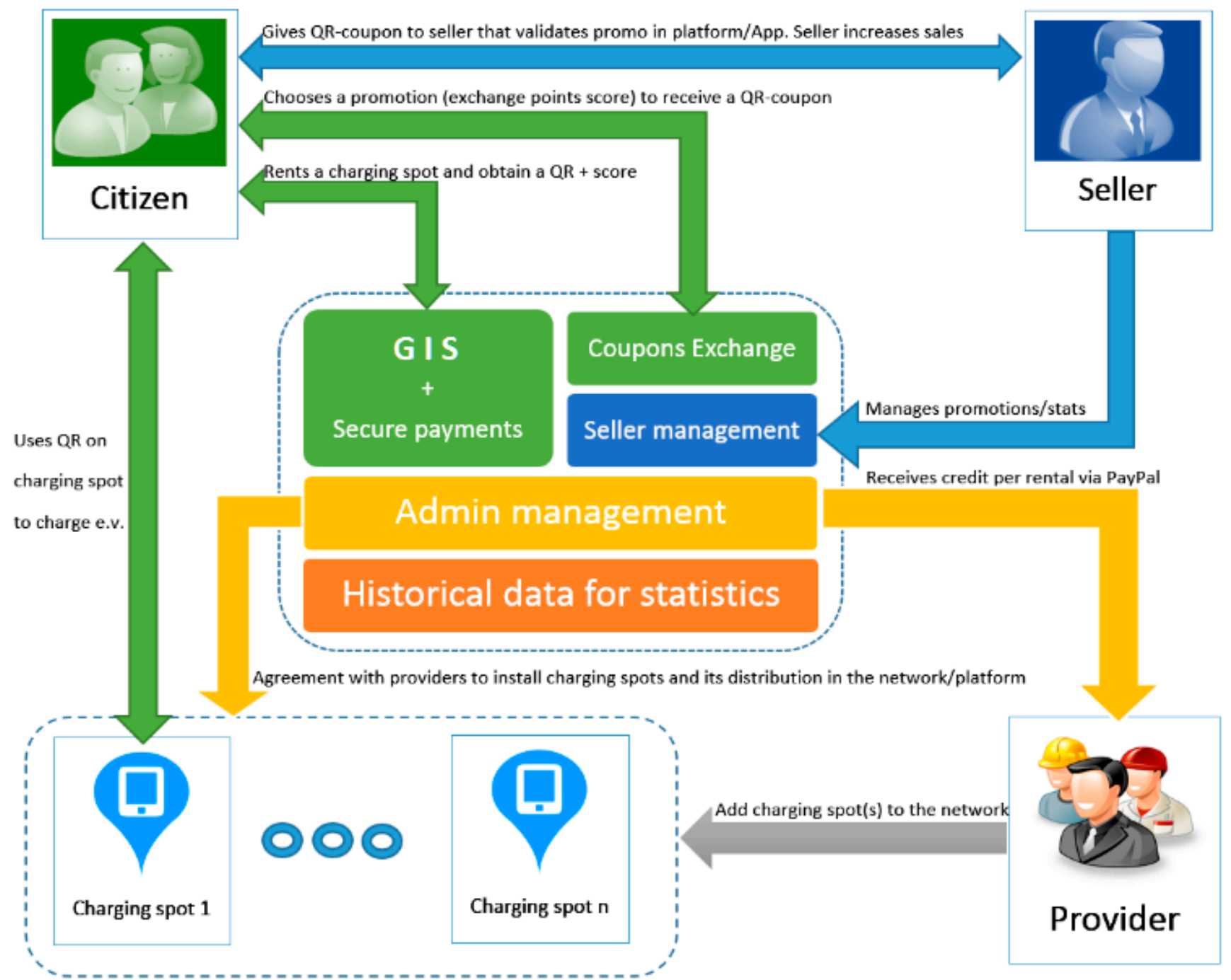

Figure 15. Electro mobility and sellers' sub-modules in the Recarga Jaen project. 


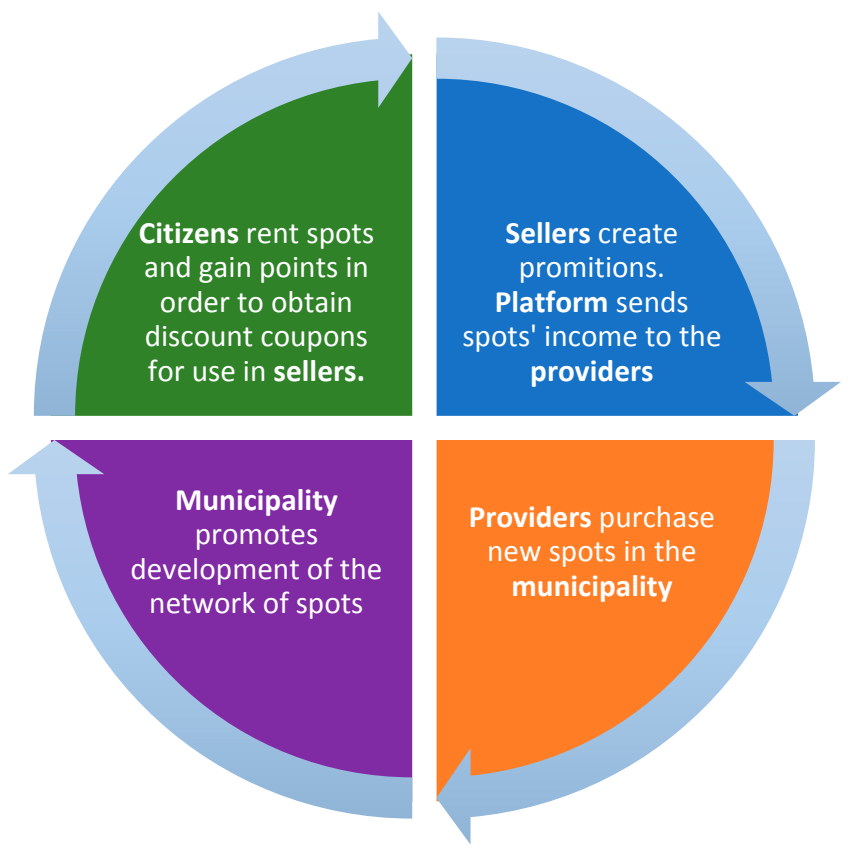

Figure 16. Sustainability of the Recarga Jaen project where the stakeholders collaborate.

\section{ISUMO Versus a Common Scenario of Transportation}

It is particularly interesting to compare ISUMO and a current common scenario of transportation (Table 5), in order to overview the increase of travel time and transport reliability, for example: "Ana is a Spanish girl with low budget who plans to go to the "Porto-Real Madrid" football match at 20:40". This example illustrates how the current scenario is more time-consuming, expensive and pollutant.

Table 5. Illustration of ISUMO versus a common scenario of transportation.

\begin{tabular}{|c|c|c|c|}
\hline Time & Current Scenario Actions & Time & ISUMO Scenario Actions \\
\hline $12: 00$ & $\begin{array}{l}\text { Ana searches in Google for cheap } \\
\text { transportation, registers, does login and } \\
\text { finds three costly choices. }\end{array}$ & $12: 00$ & $\begin{array}{l}\text { Ana registers, logs into ISUMO, } \\
\text { searches in meta-services trips and finds } \\
\text { seven cheap choices. }\end{array}$ \\
\hline $12: 45$ & Orders the trip, departs at $15 \mathrm{~h}$. & $12: 05$ & Orders the trip, departs at $13 \mathrm{~h}$. \\
\hline $15: 00$ & Departs from Madrid. & $13: 00$ & $\begin{array}{l}\text { Adds a geotrack mark (with the ISUMO } \\
\text { App for citizens) when departing. }\end{array}$ \\
\hline 20:00 & Arrives in Porto. & $18: 00$ & $\begin{array}{l}\text { Arrives in Porto and adds the final } \\
\text { geotrack mark. Increases her score and } \\
\text { Ana's } \mathrm{CO}_{2} \text { saving is calculated (also that } \\
\text { of the municipality she belongs to). }\end{array}$ \\
\hline $\begin{array}{l}20: 00 / \\
20: 20\end{array}$ & $\begin{array}{l}\text { Searches again as in the first case for how } \\
\text { to arrive at the stadium. It is far away, } \\
\text { finally decides to search for a taxi. }\end{array}$ & $\begin{array}{l}18: 00 / \\
18: 05\end{array}$ & $\begin{array}{l}\text { Uses metaservices of public } \\
\text { transportation and finds three } \\
\text { multimodal trip choices (public bus, } \\
\text { subway and trolley) combining several } \\
\text { options. }\end{array}$ \\
\hline $20: 30$ & $\begin{array}{l}\text { Finds a taxi but there is a lot of traffic and it } \\
\text { is far away from the stadium. }\end{array}$ & $\begin{array}{l}18: 07 / \\
18: 40\end{array}$ & $\begin{array}{l}\text { Adds a geotrack at the beginning and } \\
\text { end of trip, increases her score and her } \\
\text { ecological footprint is updated. }\end{array}$ \\
\hline
\end{tabular}


Table 5. Cont.

\begin{tabular}{|c|c|c|c|}
\hline Time & Current Scenario Actions & Time & ISUMO Scenario Actions \\
\hline 21:00 & Arrives late to the match. & $\begin{array}{l}18: 40 / \\
20: 40\end{array}$ & $\begin{array}{l}\text { Arrives on time, rents an ISUMO } \\
\text { charging spot (increases score and her } \\
\text { ecological footprint is updated) for } \\
\text { going to the match and testing a friend's } \\
\text { new electric car. }\end{array}$ \\
\hline \multirow{2}{*}{$\begin{array}{l}\text { The day } \\
\text { after }\end{array}$} & $\begin{array}{l}\text { Ana needs to find another transportation } \\
\text { choice, goes back to the previous websites } \\
\text { but does not find a right choice, finally } \\
\text { rents a conventional car for the trip. In } \\
\text { Madrid, she does not have coupons for } \\
\text { restaurant and eats at home. }\end{array}$ & $\begin{array}{l}\text { The day } \\
\text { after }\end{array}$ & $\begin{array}{l}\text { Exchanges her points for a " } 35 \% \text { off" } \\
\text { QR-coupon on electronic books. } \\
\text { Ana gives a printed QR-coupon code to } \\
\text { the seller who scans it with his smart } \\
\text { phone (sellers' App), validates it, and so } \\
\text { the discount is applied. }\end{array}$ \\
\hline & $\begin{array}{l}\text { Sellers and municipalities do not } \\
\text { participate, there is no additional } \\
\text { stimulation of urban economy, neither } \\
\text { reduction of greenhouse gas emissions. }\end{array}$ & & $\begin{array}{l}\text { Sellers, mobility services and charging } \\
\text { spots providers increase their business, } \\
\text { stimulating urban economy (electric cars } \\
\text { are promoted) and reducing the carbon } \\
\text { footprint of a municipality. }\end{array}$ \\
\hline
\end{tabular}

\section{Conclusions}

This model of mutual benefit among the stakeholders will increase its attractiveness and enhance awareness of sustainable mobility by revamping the behavior of "coupons culture" linked to sustainable transportation, which has worked so effectively with Nuride (with public funding) or Commute Greener, including the business model approach provided by Rappa [20] as a loyalty program of coupons for purchasing in the associated commerce. Mobility providers will also be beneficiaries due to the perceived increase in the usage of their transportation services by using multimodal transportation (similar to routeRANK). Charging spot providers will find a new business opportunity with low-cost devices, building up the necessary infrastructure to service the upcoming electric vehicle and providing a high grade of innovation in electro mobility as occurs with Autolib', as proposed by Amit and Zott [23] for business innovation in order to exploit new business opportunities in existing markets. The ISUMO platform provides interesting features such as a marketing tool for sellers willing to promote their business products or brand name with the positive input of being part of a green platform while increasing their business. On the other hand, it is perfectly possible for the self-financing option of the platform to become economically sustainable as proposed by Bocken [27] (at least to cover the costs of running the server and ICT development). This would include various monetizing methods such as advertising, premium services, monthly membership or payments as a fee (\%) for using the platform, although this is not recommended until the platform gains enough popularity in a municipality.

This work is envisaged to help all kind of organizations, from small to medium or large corporations, but especially indicated for the public sector (regions or municipalities) in order to effectively implement - partially or totally_(1) the proposed business model; (2) the ISUMO technological platform or (3) a similar solution of incentivized electro mobility as Recarga Jaen is, in the context of Smart Cities [44]. 
Regarding the Recarga Jaen project's contribution to the municipality of Jaen, to date there is a charging spot operative at the Campus of the University of Jaen (Figure 17). It is expected that the network will increase progressively, due to the agreement reached with the Municipality of Jaen in 2013 [50] and the recent inclusion [51] of the city into the most important consortium of Spanish Smart Cities - the RECI - in February 2015, and the approval on 26 March 2015 of a National Plan for Spanish Smart Cities [52] opening up a new opportunity for public funding. The solution will gather enough data to measure the mid to long-term socio-economic and environmental impacts, making it possible to conduct additional research. Finally, there is an explanatory YouTube video of the Recarga Jaen platform available [53] with English subtitles to give readers a better understanding of how the solution works.

The authors expect to disseminate this work via open access in order to reach the widest public possible and make it helpful for scholars, researchers or municipalities, so any of the ideas described may be adopted in order to generate positive urban socio-economic and environmental impacts.

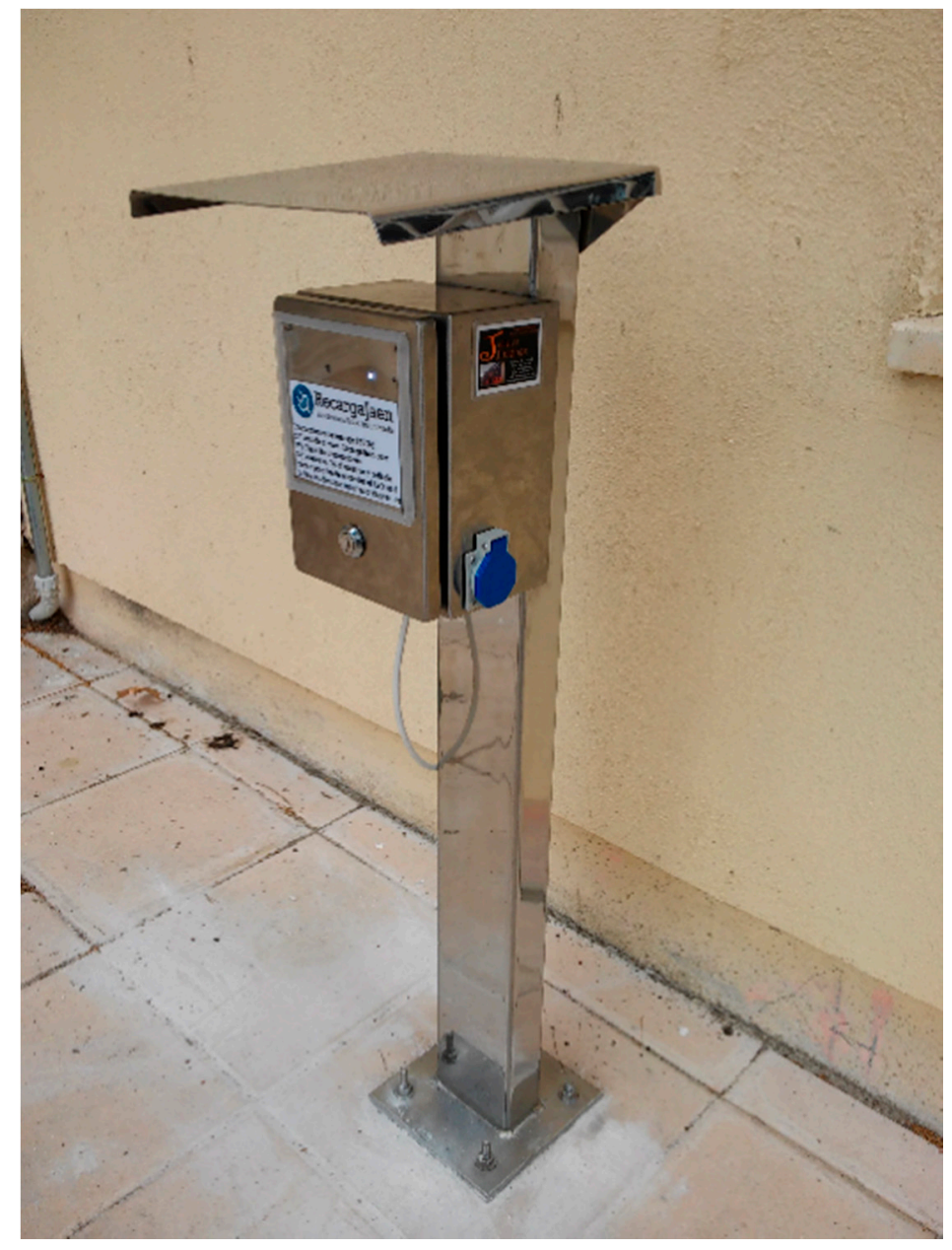

Figure 17. First public charging spot in the Municipality of Jaen, at the University of Jaen.

\section{Acknowledgments}

The Recarga Jaen project mentioned in Section 3.5 was made possible with public funding from the University of Jaen and the Municipality of Jaen. The authors would also like to thank the reviewers for supporting the work in open access for better dissemination. 


\section{Author Contributions}

Manuel Herrador who is the main author, has contributed with most of the ideas and has fully developed the above-mentioned Recarga Jaen project. Francisco R. Feito and Alexandre V. Carvalho supervised the writing of this paper. Francisco R. Feito helped in defining the overall business model. Alexandre V. Carvalho is the author of Section 3.3.

\section{Conflicts of Interest}

The authors declare no conflict of interest.

\section{References}

1. Clark, H. Davos Must Look at How War and Climate Change Affect Poverty. Available online: http://www.theguardian.com/global-development/2015/jan/22/helen-clark-davos-must-look-at-howwar-and-climate-change-poverty (accessed on 24 March 2015).

2. Reuters-Climate change fight affordable, cut emissions to zero by $2100-\mathrm{UN}$. Available Online: http://www.reuters.com/article/2014/11/02/climatechange-report-idUSL6N0SS0B820141102 (accessed on 7 May 2015).

3. Liu, Y.; Xiao, H.; Zikhali, P.; Lv, Y. Carbon Emissions in China: A Spatial Econometric Analysis at the Regional Level. Sustainability 2014, 6, 6005-6023.

4. Wang, J.; Chi, L.; Hu, X.; Zhou, H. Urban Traffic Congestion Pricing Model with the Consideration of Carbon Emissions Cost. Sustainability 2014, 6, 676-691.

5. International Energy Agency (IEA). Energy Technology Perspectives 2012; IEA: Paris, France, 2012; pp. 9-32.

6. Wang, C.; Wang, F.; Zhang, H.; Ye, Y.; Wu, Q.; Su, Y. Carbon Emissions Decomposition and Environmental Mitigation Policy Recommendations for Sustainable Development in Shandong Province. Sustainability 2014, 6, 8164-8179.

7. Towards Seamless Mobility Addressing Fragmentation in ITS Deployment in Europe. Available online: http://ec.europa.eu/research/participants/portal/desktop/en/opportunities/h2020/ topics/2618-mg-7.2b-2014.html (accessed on 24 March 2015).

8. Zhang, L.; Yang, H.; Wu, D.; Wang, D. Solving a discrete multimodal transportation network design problem. Transp. Res. Part C 2014, 49, 73-86.

9. Harris, I.; Wang, Y.; Wang, H. ICT in multimodal transport and technological trends: Unleashing potential for the future. Int. J. Prod. Econ. 2015, 159, 88-103.

10. Messagie, M.; Lebeau, K.; Coosemans, T.; Macharis, C.; van Mierlo, J. Environmental and Financial Evaluation of Passenger Vehicle Technologies in Belgium. Sustainability 2013, 5, 5020-5033.

11. Lebeau, K.; van Mierlo, J.; Lebeau, P.; Mairesse, O.; Macharis, C. Consumer attitudes towards battery electric vehicles: A large-scale survey. Int. J. Electr. Hybrid Veh. 2013, 5, 28-41.

12. Tan, Q.; Wang, M.; Deng, Y.; Yang, H.; Rao, R.; Zhang, X. The Cultivation of Electric Vehicles Market in China: Dilemma and Solution. Sustainability 2014, 6, 5493-5511. 
13. Litman, T.A. Sustainable Transportation Indicators: A Recommended Research Program for Developing Sustainable Transportation Indicators and Data. In Proceedings of the Transportation Research Board 88th Annual Meeting, Washington, DC, USA, 11-15 January 2009.

14. Onat, N.C.; Kucukvar, M.; Tatari, O. Towards Life Cycle Sustainability Assessment of Alternative Passenger Vehicles. Sustainability 2014, 6, 9305-9342.

15. Nuride. Get Rewards for Greener Trips. Available online: http://www.nuride.com (accessed on 24 March 2015).

16. Electromovilidad Incentivada, Abierta y Low-Cost de Jaen-RecargaJaen.Com. Available online: http://www.recargajaen.com (accessed on 24 March 2015).

17. Magretta, J. Why Business Models Matter. Available online: https://hbr.org/2002/05/why-businessmodels-matter (accessed on 24 March 2015).

18. Amit, R.; Zott, C. Value creation in E-business. Strateg. Manag. J. 2001, 22, 493-520.

19. Zott, C.; Amit, R.; Massa, L. The business model: Recent developments and future research. J. Manag. 2011, 37, 1019-1042.

20. Rappa, M. Managing the Digital Enterprise. Business Models on the Web, 2003. Available online: http://digitalenterprise.org/models/models.html (accessed on 24 March 2015).

21. Dobosson-Torbay, M.; Osterwalder, A.; Pigneur, Y. E-Business Model Design, Classification, and Measurements. Thunderbird Int. Bus. Rev. 2002, 44, 5-23.

22. Osterwalder, A.; Pigneur, Y. Business Model Generation: A Handbook for Visionaries, Game Changers, and Challengers Paperback; John Wiley and Sons: Hoboken, NJ, USA, 2010.

23. Amit, R.; Zott, C. Creating value through business model innovation. MIT Sloan Manag. Rev. 2012, $53,41-49$.

24. Schaltegger, S.; Lüdeke-freund, F.; Hansen, E. Business Cases for Sustainability and the Role of Business Model Innovation Developing a Conceptual Framework, Lueneburg: Centre for Sustainability Management (CSM); Leuphana University of Lueneburg: Lueneburg, Germany, 2011.

25. Lüdecke-Freund, F. Towards a conceptual framework of business models for sustainability. In Proceedings of the ERSCP-EMSU 2010 Conference-Knowledge Collaboration \& Learning for Sustainable Innovation, Delft, The Netherlands, 25-29 October 2010; pp. 1-28.

26. Stubbs, W.; Cocklin, C. Conceptualizing a "Sustainability business model”. Organ. Environ. 2008, 21, 103-127.

27. Bocken, N.; Short, S.; Rana, P.; Evans, S. A value mapping tool for sustainable business modelling. Corp. Gov. 2013, 13, 482-497.

28. Bocken, N.; Short, S.; Rana, P.; Evans, S. A literature and practice review to develop sustainable business model archetypes. J. Clean. Prod. 2014, 65, 42-56.

29. Bocken, N.; Short, S.W.; Rana, P. Value mapping for sustainable business thinking. J. Ind. Prod. Eng. 2015, 32, 1-15.

30. Wells, P. Creating sustainable business models: The case of the automotive industry. IIMB Managament Review. Creating Sustainable Business Models: The Case of the Automotive Industry; Indian Institute of Management Bangalore: Bangalore, India, 2014; Volume 16, pp. 15-24.

31. An Interview with Rick Steele, Co-Founder and CEO, Nuride. Available online: http://www.nvtc.org/ tec/RickSteele.php (accessed on 24 March 2015). 
32. The Future of Trip Reduction. Available online: http://www.slideshare.net/nurider/nuridepresentation-for-act-patriot-conf-jun-10 (accessed on 24 March 2015).

33. The Fastest and Cheapest Way from A to B. Available online: http://www.routerank.com (accessed on 24 March 2015).

34. “A Well-Conceived Business Model”. Succeed. The European Business Magazine, 2012. Available online: http://www.routerank.com/_downloads/press/01072012-SUCCEED.pdf (accessed on 24 March 2015).

35. Davidson, A. How Much Time, Money and $\mathrm{CO}_{2}$ Emissions Could routeRANK Save a Typical Travel Planner? Master's Thesis, University of Cambridge, Cambridge, UK, 2009.

36. How to Use Autolib'? Follow the Guide! Available online: https://www.autolib.eu/en/how-does-itwork/service/ (accessed on 24 March 2015).

37. Autolib' Electric Carsharing Program. Available online: http://cleantechnica.com/2014/04/02/ autolib-electric-carsharing-program/ (accessed on 24 March 2015).

38. French technology, innovation set for global invasion. Available online: http://www.themalaymailonline.com/tech-gadgets/article/french-technology-innovation-set-forglobal-invasion (accessed on 7 May 2015).

39. Weiller, C. E-Mobility Services. New Economic Models for Transport in the Digital Economy. Case Study for Research Council UK Digital Economy Theme. Available online: http://www.cambridgeservicealliance.org/uploads/downloadfiles/E-Mobility\%20Services.pdf (accessed on 24 March 2015).

40. Kouwenhoven, M.; Kroes, E.; Tardivel, E.; Gazave, C. Estimating Potential Demand for Autolib'-A New Transport System for Paris. In Proceedings of the International Choice Modelling Conference, Leeds, UK, 4-6 July 2011.

41. Rethinking Transportation, pp. 18-40. Available online: www3.volvo.com/investors/finrep/sr13/ pdf/part2/Rethinking_transportation.pdf (accessed on 24 March 2015).

42. Bocken, N.; Allwood, J. Strategies to reduce the carbon footprint of consumer goods by influencing stakeholders. J. Clean. Prod. 2012, 35, 118-129.

43. Kuschel, M. Commute Greener! Innovation for Business: Innovating Smarter Futures. In Proceedings of the XXIV ISPIM Conference, Helsinki, Finland, 16-19 June 2013.

44. Paskaleva, K. Enabling the Smart City: The Progress of E-city Governance in Europe. Int. J. Innov. Reg. Dev. 2009, 1, 405-422.

45. 2 Billion Consumers Worldwide to Get Smart (Phones) by 2016. Available online: http://www.emarketer.com/Article/2-Billion-Consumers-Worldwide-Smartphones-by-2016/ 1011694 (accessed on 24 March 2015).

46. QR Code Usage Among European Smartphone Owners Doubles Over Past Year. Available online: http://www.comscore.com/Insights/Press-Releases/2012/9/QR-Code-Usage-Among-EuropeanSmartphone-Owners-Doubles-Over-Past-Year (accessed on 24 March 2015).

47. Lenglet, F. Can ESD Reach the Year 2020? J. Educ. Sustain. Dev. 2014, 8, 121-125.

48. Caperello, N.; Kurani, K.S.; Tyree-Hageman, J. Do You Mind if I Plug-in My Car? How Etiquette Shapes PEV Drivers' Vehicle Charging Behavior. Available online: http://www.its.ucdavis.edu/wpcontent/themes/ucdavis/pubs/download_pdf.php?id=1952 (accessed on 24 March 2015). 
49. Mendes, M.; Moura, F.; Martinez, L.M. A rule-based approach for determining the plausible universe of electric vehicle buyers in the Lisbon Metropolitan Area. Transport. Res. Part A 2014, 59, 22-36.

50. Agreement of the University of Jaen with the Municipality of Jaen. Available online: http://www.SmartCityJaen.com/agreement.pdf (accessed on 30 April 2015). (In Spanish)

51. Inclusion of the Municipality of Jaen into the RECI Consortium. Available online: http://www.redciudadesinteligentes.es/noticias/ampliar.php/Id_contenido/1241/ (accessed on 30 April 2015). (In Spanish)

52. Plan for Spanish Smart Cities. Available online: https://www.esmartcity.es/noticias/aprobado-elplan-nacional-de-ciudades-inteligentes-para-espana (accessed on 30 April 2015). (In Spanish)

53. Explanatory Video of the Recarga Jaen Platform with English Subtitles. Available online: https://www.youtube.com/watch?v=iaP_L7WVgsI (accessed on 30 April 2015).

(C) 2015 by the authors; licensee MDPI, Basel, Switzerland. This article is an open access article distributed under the terms and conditions of the Creative Commons Attribution license (http://creativecommons.org/licenses/by/4.0/). 